\title{
Development of the Real-time On-road Emission (ROE v1.0) model for street-scale air quality modeling based on dynamic traffic big data
}

\author{
Luolin $\mathrm{Wu}^{1}$, Ming Chang ${ }^{2}$, Xuemei Wang ${ }^{2}$, Jian Hang ${ }^{1}$, Jinpu Zhang ${ }^{3}$, Liqing Wu ${ }^{1}$, and Min Shao ${ }^{2}$ \\ ${ }^{1}$ School of Atmospheric Sciences, Sun Yat-sen University, Guangzhou 510275, P. R. China \\ ${ }^{2}$ Institute for Environmental and Climate Research, Jinan University, Guangzhou 510632, P. R. China \\ ${ }^{3}$ Guangzhou Environmental Monitoring Center, Guangzhou 510030, P. R. China
}

Correspondence: Xuemei Wang (eciwxm@jnu.edu.cn)

Received: 25 March 2019 - Discussion started: 10 April 2019

Revised: 3 July 2019 - Accepted: 13 August 2019 - Published: 3 January 2020

\begin{abstract}
Rapid urbanization in China has led to heavy traffic flows in street networks within cities, especially in eastern China, the economically developed region. This has increased the risk of exposure to vehicle-related pollutants. To evaluate the impact of vehicle emissions and provide an on-road emission inventory with higher spatiotemporal resolution for street-network air quality models, in this study, we developed the Real-time On-road Emission (ROE v1.0) model to calculate street-scale on-road hot emissions by using real-time big data for traffic provided by the Gaode Map navigation application. This Python-based model obtains street-scale traffic data from the map application programming interface (API), which are open-access and updated every minute for each road segment. The results of application of the model to Guangzhou, one of the three major cities in China, showed on-road vehicle emissions of carbon monoxide $(\mathrm{CO})$, nitrogen oxide $\left(\mathrm{NO}_{x}\right)$, hydrocarbons $(\mathrm{HCs})$, $\mathrm{PM}_{2.5}$, and $\mathrm{PM}_{10}$ to be $35.22 \times 10^{4}, 12.05 \times 10^{4}, 4.10 \times 10^{4}$, $0.49 \times 10^{4}$, and $0.55 \times 10^{4} \mathrm{Mg} \mathrm{yr}^{-1}$, respectively. The spatial distribution reveals that the emission hotspots are located in some highway-intensive areas and suburban town centers. Emission contribution shows that the dominant contributors are light-duty vehicles (LDVs) and heavy-duty vehicles (HDVs) in urban areas and LDVs and heavy-duty trucks (HDTs) in suburban areas, indicating that the traffic control policies regarding trucks in urban areas are effective. In this study, the Model of Urban Network of Intersecting Canyons and Highways (MUNICH) was applied to investigate the impact of traffic volume change on street-scale pho-
\end{abstract}

tochemistry in the urban areas by using the on-road emission results from the ROE model. The modeling results indicate that the daytime $\mathrm{NO}_{x}$ concentrations on national holidays are $26.5 \%$ and $9.1 \%$ lower than those on normal weekdays and normal weekends, respectively. Conversely, the national holiday $\mathrm{O}_{3}$ concentrations exceed normal weekday and normal weekend amounts by $13.9 \%$ and $10.6 \%$, respectively, owing to changes in the ratio of emission of volatile organic compounds (VOCs) and $\mathrm{NO}_{x}$. Thus, not only the on-road emissions but also other emissions should be controlled in order to improve the air quality in Guangzhou. More significantly, the newly developed ROE model may provide promising and effective methodologies for analyzing real-time street-level traffic emissions and high-resolution air quality assessment for more typical cities or urban districts.

\section{Introduction}

Rapid economic development and urbanization have led to an exponential growth in the number of vehicles in China in recent years (National Bureau of Statistics of China, 2017). As one of the three major urban clusters, the Pearl River Delta (PRD) region, or its main city Guangzhou, has experienced a significant increase in the number of vehicles. This increase has become the dominant contributor to carbon monoxide $(\mathrm{CO})$, nitrogen oxide $\left(\mathrm{NO}_{x}\right)$, and hydrocarbon $(\mathrm{HC})$ emissions (He et al., 2002; Zheng et al., 2009a), which in turn are causing more frequent and more severe public health 
problems in Chinese megacities (An et al., 2013). Previous studies have shown that on-road vehicle emissions can contribute approximately $22 \%-52 \%$ of total CO, $37 \%-47 \%$ of total $\mathrm{NO}_{x}$, and $24 \%-41 \%$ of total $\mathrm{HC}$ emissions detected in cities (Zhang et al., 2009; Zheng et al., 2009a, 2014; Li et al., 2017).

Reliable on-road emission inventories can be used as input data for the numerical air quality models which are applied to estimate the impact of on-road emissions on the urban air quality (Wang and Xie, 2009; He et al., 2016). For this purpose, a realistic on-road vehicle emission inventory should be developed for this pollution source. The two main methodologies used in recent years to establish such inventories are top-down and bottom-up techniques.

Top-down methods, such as that used in the MOBILE model devised by the US Environmental Protection Agency (EPA, 2003) and other similar macroscale models, first require information on vehicle population, vehicle kilometers traveled (VKT), and mean vehicle speed for an entire city to calculate the total amount of vehicular emissions. Then, the emissions are allocated to each grid cell utilizing parameters such as road density and road hierarchy (Saide et al., 2009; Jing et al., 2016; Liu et al., 2018). Many studies have adopted this method to develop city- or national-level vehicle emission inventories in China (Hao et al., 2000; Cai and Xie, 2007; Guo et al., 2007; Saide et al., 2009; Zheng et al., 2009a; Sun et al., 2016). However, the top-down inventories offer low-level spatial and temporal resolutions because of the allocation method and input data used. Typically, the spatial allocation of a top-down inventory is based on the road network. The greater the road density and length, the higher the amount of emissions in the same grid. This allocation method simplifies the road emissions by assuming that every road of a specific road type (e.g., highway, arterial road, or local road) experiences the same traffic volume irrespective of its location. In addition, emission factors are considered to remain unchanged despite the traffic speed over the entire city, thereby leading to inaccurate results for the inventory. Moreover, some megacities (e.g., Guangzhou) have traffic control policies in place in certain urban areas, which implies that the emissions should differ across areas. Besides, the VKT data are usually provided on the yearly scale, which limits the temporal resolution of the inventory. For numerical modeling, the accuracy of the emission inventory may have a great impact on the simulation results because of the strong dependence of numerical models on it (Jing et al., 2016). This scale of the emission inventory may not reflect the real emission conditions for the on-road vehicles within the city, and thus evaluations of traffic-related impacts on air pollution in complex situations such as street-level traffic flow are likely to be inaccurate (Huo et al., 2009).

Consequently, several studies have established higherresolution inventories using the bottom-up approach. The main difference from the top-down method is that bottomup inventories are based on information from road segments.
Therefore, spatial distribution is directly obtained from the input data and spatial and temporal allocations are not required. Among the input data, the traffic data are crucial for establishing the inventories and determining their accuracy. Some previous studies have used traffic simulation models to obtain traffic speed or volume data of road networks (Pallavidino et al., 2014; Zhang et al., 2016; Chen et al., 2017; Ibarra-Espinosa et al., 2018). Based on the traffic model, the method could provide traffic data for each road from lowresolution average data. However, the results from such traffic models may not reflect reality, thereby reducing the accuracy of the inventories. Many other studies have used realistic traffic data, namely road-side or on-board observational data obtained at certain road segments, to establish inventories and improve their accuracy (Huo et al., 2009; Wang et al., 2008, 2010; Wang and Xie, 2009; Yao et al., 2013). Although the observed traffic data are helpful for inventory establishment, their limitation is obvious in that large-scale observation for a whole city requires extensive human labor and financial and material resources, which are expensive and time consuming. Moreover, such observations may not provide real-time traffic data, thereby reducing the temporal resolution of the inventories.

Recent developments in image identification technology and other observation detectors are facilitating easy collection of real-time traffic data from road networks. The extensive implementation of closed-circuit televisions and other detection subsystems in cities helps intelligent transport systems (ITSs) in China (Wu et al., 2009), making it possible to attain real-time traffic data at the city scale. Using the traffic data provided by ITSs, many previous studies have successfully developed inventories for different areas in China (Jing et al., 2016; Liu et al., 2018; Zhang et al., 2018). Such studies provided us with a new direction for the establishment of bottom-up inventories. The real-time traffic data from the road network could be the most precise input data for onroad emission inventories and could significantly improve the spatial and temporal resolutions of the inventories. However, there are still some difficulties in using the ITS data. In some cities, construction of the ITS is not complete yet or has not even been carried out. Moreover, the inconsistency of the data standards leads to an inefficient way of data utilization (Zhang, 2010). Furthermore, the low degree of data sharing may be the biggest barrier to using traffic data obtained from the ITSs (Huang et al., 2017).

With the help of a high-resolution emission inventory, numerical models can assess the impact of on-road vehicle emissions on the air quality (Huo et al., 2009). The air flow and air quality modeling in cities are commonly categorized into four groups by length scales, i.e., street scale $(\sim 100 \mathrm{~m})$, neighborhood scale $(\sim 1 \mathrm{~km})$, city scale $(\sim 10 \mathrm{~km})$, and regional scale $(\sim 100 \mathrm{~km})$ (Britter and Hanna, 2003). A previous comprehensive literature review on this topic (Zhang et al., 2012) reports that regional-scale chemical transport models (CTMs) have been widely applied to investigate the 
chemistry and transport of air pollutants from their emission sources. Many studies have successfully applied regionalscale CTMs to investigate the impact of on-road vehicles on the air quality in urban areas in the regional scale $(\sim 100 \mathrm{~km})$ (Che et al., 2011; Saikawa et al., 2011; He et al., 2016; Ke et al., 2017). In addition, some researchers have studied streetscale and neighborhood-scale pollutant dispersion and urban air quality by adopting computational fluid dynamics (CFD) models (Fernando et al., 2010; Kim et al., 2012; Kwak et al., 2013; Kwak and Baik, 2014; Park et al., 2015; Zhong et al., 2016; Hang et al., 2017). City-scale ( $10 \mathrm{~km})$ CFD modeling, however, usually requires consideration of billions of grids because a city may include tens of thousands of buildings with high-resolution and complex street networks (Di Sabatino et al., 2008; Ashie and Kono, 2011). Thus, as cityscale CFD simulations are very expensive and time consuming, they are currently rare. Recently, some models have been developed and applied to investigate street-level air quality at the city scale (Davies et al., 2007; Righi et al., 2009; Zhang et al., 2016; Kim et al., 2018) by balancing the requirements of high resolution and low computational cost.

In this direction, the first purpose of this study was to find a new open-access source of real-time and high-quality traffic data that could serve as the input for developing an onroad emission inventory with high spatial and temporal resolutions for cities or urban districts. Guangzhou was selected as the target city for the initial application of this method not only because of the large number of vehicles in use there but also because of its well-developed ITS which could obtain the traffic information from street networks (Xiong et al., 2010). A Python-based on-road emission model called the Real-time On-road Emission (ROE v1.0) model was developed in this study to utilize these traffic data and establish a bottom-up on-road emission inventory. A street-level chemistry transport model was then used to apply the emission results and study the impact of traffic volume variations on the air quality in the urban districts of Guangzhou.

\section{Description of the ROE model}

\subsection{Model overview}

The ROE model is intended to establish the street-level emission inventories using the emissions of on-road vehicles in the street segments of interest using a bottom-up approach. First, the ROE model collects the real-time traffic information to obtain the traffic volume for each street segment from the ITS. Then, according to the vehicle fleet information, the ROE model calculates the number of vehicles for each vehicle category on each street segment (if available, these data could be obtained from the ITS and need not be calculated by model). Thereafter, the ROE model calculates the emissions for street segments based on the vehicle fleet information, traffic conditions, and environmental conditions. Lastly, the
ROE model outputs the results, i.e., street-level air quality inventories.

\subsection{Model structure}

The ROE model was developed to calculate on-road vehicle emissions from real-time traffic data. The structure of the model is shown in Fig. 1. The model, which has been implemented in Python 3, can be divided into four modules: crawler, preprocessing, emissions calculation, and output modules.

1. The most crucial part of the emission inventory involves obtaining the real-world traffic data. The crawler module is designed for crawling the real-time traffic data from the ITS, Internet, or any other data source if the code is updated to match the format of the data source. Moreover, the study area should be set in the module and, if needed (in case the coordinates differ), the coordinate transformation script should be activated. The current version of the ROE model includes the crawler module for the https://www.amap.com (last access: 2 September 2019) (also called the Gaode Map) application (Fig. 2), a widely adopted map application in China (additional details are provided in Sect. 2.4).

2. The preprocessing module is used for fitting the time frequency between the data source and the air quality modeling system. Subsequently, the traffic volume data are also calculated from the traffic speed data in this module if the traffic volume or vehicle fleet information is not available from the data source. Otherwise, the number of vehicles in each category can be used directly for the emissions calculation.

3. The emissions calculation module uses traffic information from the preprocessing module and information about vehicle fleets to calculate emissions for each street segment using the following equation:

$E_{s, t}=\sum \mathrm{EF}_{s, v} \times V_{v, t} \times L$,

where $E_{s, t}$ is the emission of pollutant $s$ at time $t$ $\left(\mathrm{gh}^{-1}\right), \mathrm{EF}_{s, v}$ is the emission factor of pollutant $s$ for vehicle category $v\left(\mathrm{~g} \mathrm{~km}^{-1}\right), V_{v, t}$ is the traffic volume of the vehicle (i.e., the number of vehicles) category $v$ at time $t$ (vehicles per hour), and $L$ is the length of the street segment $(\mathrm{km})$. The total emission in one specific area is given by the sum of emissions in every street segment within the area.

4. The output module sums up all the information given by the emissions calculation module and can be modified to provide all the results produced during the calculation of the emissions. In addition, the model includes a tool that can modify the formats of the emissions, making it possible to provide the on-road emissions to other air quality models. 


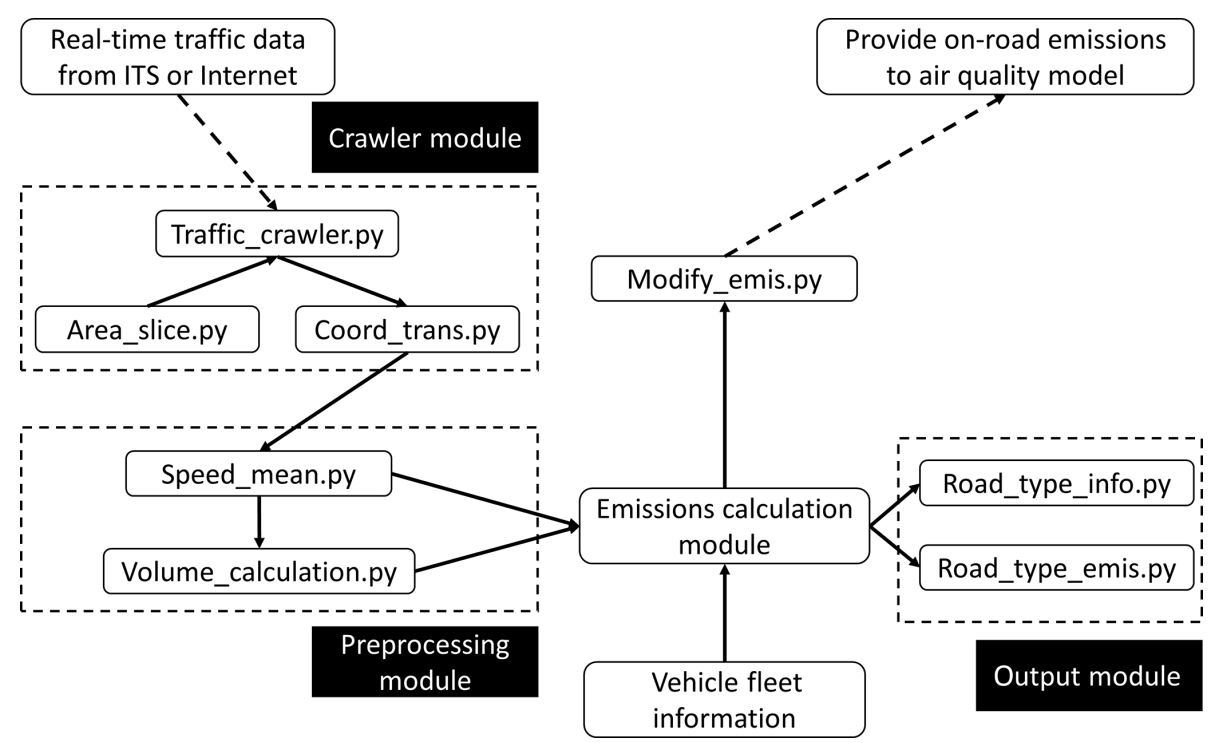

Figure 1. The structure of the ROE model.

\subsection{Emission factors}

In this study, nationwide vehicle emission factors mandated by the Ministry of Ecology and Environment (MEP) of the People's Republic of China were adopted to calculate the on-road vehicle emissions (MEP, 2014). They are listed in Tables S1 and S2 in the Supplement. The emission factors of liquefied petroleum gas (LPG) vehicles were sourced from a previous study conducted in Guangzhou (Zhang et al., 2013). According to the MEP guide, vehicles are classified as one of the following: a light-duty vehicle (LDV), a middle-duty vehicle (MDV), a heavy-duty vehicle (HDV), a light-duty truck (LDT), a middle-duty truck (MDT), a heavy-duty truck (HDT), a motorcycle (MC), a taxi, or a bus. The fuel type is classified as petrol, diesel, or other (such as LPG or natural gas). The emission standard is classified as Pre-China I, China I, China II, China III, China IV, or China V. In addition, the evaporation of petrol was considered during the calculation of the emissions. HC evaporation was also considered as per the details provided in the MEP guidebook (Table S3).

The correction factors involving environmental conditions (e.g., temperature, relative humidity, and altitude) and traffic conditions obtained from the technical guide were considered in the study. They are listed in Tables S4-S10 in the Supplement. These correction factors were applied to reduce the effects of uncertainties associated with the emission factors.

To estimate the uncertainties in the emissions factors, the results of previous studies (Zheng et al., 2009a; Zhang et al., 2013, 2016; Tang et al., 2016; Wang et al., 2017) were summarized and compared with the emission factors obtained in this study. These results appear in Fig. S1 of the Supplement.
In addition, the emission factors can be easily updated once the local emission factor data are available.

\subsection{Traffic data from floating car data}

In this study, the traffic speed data of each street segment were obtained from Gaode Map. The Gaode Map traffic data are quite extensive as they cover over 40 cities in China so far (with most of them being major cities). Based on GPS and mobile network information, details on vehicle speed and location are collected from the map users' devices while using the map navigation on the road. This aspect saves a considerable amount of human labor and material resources with regard to traffic condition observations. These data are updated in real time and can be used through an open-access application programming interface (API), thus overcoming the barrier of obtaining data. As the data can be updated in real time, the emission data can also be refreshed in real time.

However, the map application cannot provide the traffic volume data directly. Many studies have shown that the traffic volume can be estimated using the average traffic speed based on the relationship between the traffic speed and the volume (Wang, 2003; Xu et al., 2013; Wang et al., 2013; Yao et al., 2013; Hooper et al., 2014; Jing et al., 2016). Many speed-flow models exist for this purpose and each of them has certain advantages and disadvantages. In this study, the Underwood volume calculation model (Underwood, 1961) was used to retrieve the information on traffic volume because of its history of successful application in China (Jing et al., 2016). The model is described by Eq. (2):

$V=k_{m} u \ln \frac{u_{\mathrm{f}}}{u}$, 
where $V$ is the traffic volume at speed $u$ (vehicles per hour), $k_{m}$ is the traffic density (vehicles per kilometer), $u$ is the traffic speed $\left(\mathrm{km} \mathrm{h}^{-1}\right)$, and $u_{\mathrm{f}}$ is the free speed $\left(\mathrm{km} \mathrm{h}^{-1}\right)$. In this study, $k_{m}$ and $u_{\mathrm{f}}$ are given by fitting the model based on observation data obtained at the roadside and video identification data gained from different road types (Zheng et al., 2009a; Jing et al., 2016; Liu et al., 2018).

To calculate the traffic volume on national highways, another speed-flow model, which was previously applied in an observation-based study undertaken in China (Wang, 2003), was used. This model is described as follows.

When the speed limit is $120 \mathrm{~km} \mathrm{~h}^{-1}$,

$V=-0.611 u^{2}+73.320 u$

when the speed limit is $100 \mathrm{~km} \mathrm{~h}^{-1}$,

$V=-0.880 u^{2}+88.000 u$

when the speed limit is $80 \mathrm{~km} \mathrm{~h}^{-1}$,

$V=-1.250 u^{2}+100.000 u$

when the speed limit is $60 \mathrm{~km} \mathrm{~h}^{-1}$,

$V=-2.000 u^{2}+120.000 u$

where $V$ is the traffic volume at speed $u$ (vehicles per hour) and $u$ is the traffic speed $\left(\mathrm{km} \mathrm{h}^{-1}\right)$.

Given Guangzhou's traffic control policies, the whole city is divided into two areas: urban area and suburban (Fig. 3). Therefore, the traffic volume is also calculated accordingly (Fig. 4). The main traffic control policies in urban areas are as follows: (1) no truck is allowed to enter the urban area during 07:00-09:00 LT (all times in this paper are local time, LT) (morning rush hours) and 18:00-20:00 (evening rush hours), (2) no middle- and heavy-duty truck is permitted to enter the urban area during 07:00-22:00, (3) no nonlocal truck can enter the urban area during 07:00-22:00, and (4) no motorcycle can enter the urban area.

\subsection{Vehicle fleet information}

In this study, the fleet information on each vehicle classification was sourced from the Guangzhou Statistical Yearbook (Guangzhou Bureau of Statistics, 2017) (Fig. 5a). The emission standards (Fig. 5b) and fuel type data (Fig. 6) for the vehicles were sourced from previous studies undertaken in Guangzhou (Zhang et al., 2013, 2015). Due to the lack of street-level vehicle fleet information, this study used a uniform percentage of emission standard, fuel type, and number of vehicles in each category for each segment. The number of each vehicle type was calculated based on the total traffic volume of each street segment and the vehicle fleet percentage. It should be noted that this information could be updated if the street-level fleet information becomes available in the future.

\section{Description of the street-level air quality model}

To evaluate the impact of on-road emissions on air quality at the street level in Guangzhou, an air quality model called the Model of Urban Network of Intersecting Canyons and Highways (MUNICH) was employed in this study with the on-road emission results from the ROE model. MUNICH is a street-network CTM that includes street-canyon and streetintersection components in the model (Kim et al., 2018).

In this study, the Weather Research and Forecasting (WRF) model (version 3.7.1) (Skamarock et al., 2008) was used to provide the meteorological data (wind profile, boundary-layer height, and friction velocity) for the modeling. The WRF simulation was conducted with four nested domains at resolutions of 27, 9, 3, and $1 \mathrm{~km}$ (Fig. 7a). The physical scheme is listed in Table 1.

In MUNICH, the CB05 chemical kinetic mechanism (Yarwood et al., 2005) was used to simulate the photochemical reactions at the street level in an urban street network. For the MUNICH run, the model was applied to simulate pollutant dispersion in Tianhe District, which serves as the central business district (CBD) of Guangzhou. The district is characterized by significant diurnal traffic variation compared with other districts in urban areas. The simulation area comprised 31 main street segments selected to simulate the variation in pollutant concentrations because continuous traffic data existed for these street segments during the simulation period, which were representative of the street network.

The urban morphology data for the building height were obtained from the World Urban Database and Access Portal Tools (WUDAPT) dataset (Ching et al., 2018). The street data were sourced from the OpenStreetMap dataset (https: //www.openstreetmap.org/, last access: 2 September 2019). The street length data were calculated directly from the locations of the start and end intersections of each street segment. Data on the street width were retrieved from the feature class of the road and the width of each lane was assumed to be $3.5 \mathrm{~m}$.

The simulation period of the study spanned from 28 April to 2 May 2018, which included a Chinese national holiday from 29 April to 1 May 2018. Significant traffic volume change exists between the holidays and nonholidays. This simulation period covered holidays and nonholidays, which was helpful to investigate the impact of traffic volume variations on air quality. Another $3 \mathrm{~d}$ simulation period was conducted before this period to spin up the model.

For modeling evaluation and background concentrations, the observational concentration data for $\mathrm{NO}_{2}$ and $\mathrm{O}_{3}$ were obtained from the Guangzhou environmental monitoring sites network. $\mathrm{NO}_{2}$ concentrations were measured with a chemiluminescence instrument (model 42i, Thermo Scientific) and $\mathrm{O}_{3}$ was measured by a UV photometric analyzer (model 49i, Thermo Scientific). The minimum detection limit $(3 \mathrm{~S} / \mathrm{N}$ ) of the analyzer was $0.4 \mathrm{ppbV}$ (approximately $0.8 \mu \mathrm{g} \mathrm{m}^{-3}$ ) for $\mathrm{NO}_{2}$ and $1.0 \mathrm{ppbV}$ (approximately 


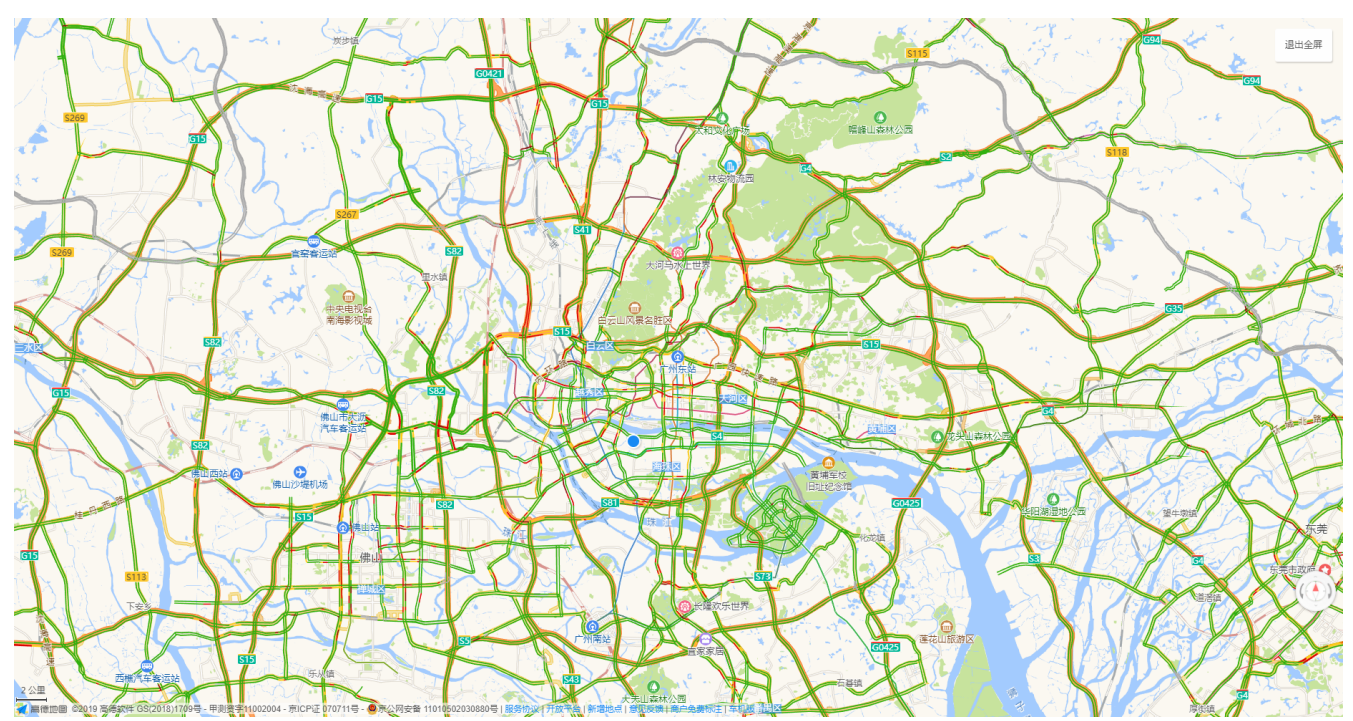

Figure 2. Traffic information from Gaode Map (@ 2019).

Table 1. Physical parameterization configurations for WRF v3.7.1 model.

\begin{tabular}{ll}
\hline Physical parameterizations & \\
\hline Microphysics scheme & Morrison (2 moments) (Morrison et al., 2009) \\
Land-surface scheme & Pleim-Xiu (Xiu and Pleim, 2001) \\
Cumulus scheme & Kain-Fritsch (Kain, 2004) \\
Longwave radiation scheme & Rapid Radiative Transfer Model (RRTM) (Mlawer et al., 1997) \\
Shortwave radiation scheme & Dudhia (Dudhia, 1989) \\
Boundary-layer scheme & Asymmetric Convective Model version 2 (ACM2) (Pleim, 2007) \\
Urban surface scheme & Urban Canopy Model (UCM) (Chen et al., 2011) \\
\hline
\end{tabular}

$2.0 \mu \mathrm{g} \mathrm{m}^{-3}$ ) for $\mathrm{O}_{3}$. The total measurement uncertainty in these two instruments was estimated to be approximately $5 \%$ (Zhang et al., 2014).

Two monitoring sites, Tiyuxi (TYX) site and YangJi (YJ) site, were selected for this study (Fig. 7c). The observational data from TYX were used for modeling evaluation because TYX is located inside the simulation area and thus these data could be used for comparison with the model results. In addition, YJ is located near but not within the simulation street network. The observational data from YJ could be used as the background concentration data for the modeling. Due to the lack of NO observational data, the concentration ratio of $\mathrm{NO}_{2}$ to $\mathrm{NO}$ was assumed as $4: 1$ in this study.

\section{Application of the ROE model to Guangzhou}

\subsection{On-road emission inventory from the ROE model}

\subsubsection{Overview of the emission inventory}

Using the high-resolution spatial and temporal traffic data from the map application, the emission inventory of on- road vehicles from the ROE model was established for this study. Table 2 shows the annual emissions from vehicles in Guangzhou city compared with two other gridded emission inventories in China: the MEIC model (http://www. meicmodel.org/, last access: 2 September 2019) and a PRD region local emission inventory (Zheng et al., 2009b). These two emission inventories used the top-down method to establish on-road emission inventories. Unlike the bottom-up method used in this study, these two inventories first calculated the total emissions based on the VKT data of vehicle categories. In the MEIC inventory, the total number of vehicles was obtained from the relationship between total vehicle ownership and economic development (Zheng et al., 2014), while the PRD inventory acquired information on the number of vehicles from the city-level Guangzhou Statistical Yearbook. Then, the spatial distribution of these two inventories was established based on the road network density.

Given the shorter total road length and traffic control policies in urban areas (Fig. 3), the urban on-road emissions of $\mathrm{CO}, \mathrm{NO}_{x}, \mathrm{HC}, \mathrm{PM}_{2.5}$, and $\mathrm{PM}_{10}$ comprised only $13.1 \%$, $8.8 \%, 12.7 \%, 8.2 \%$, and $9.1 \%$ of the total on-road emis- 


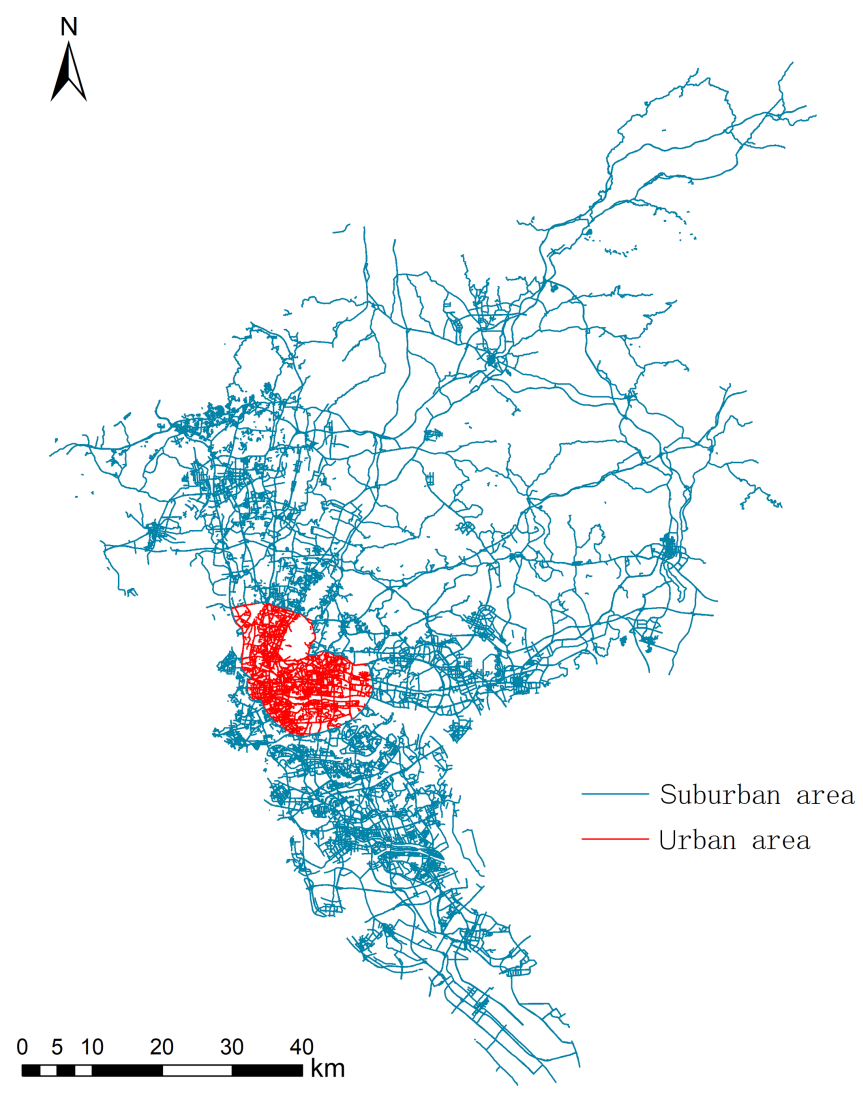

Figure 3. Traffic control area.

Table 2. Annual on-road emissions in Guangzhou (unit: $\left.10^{4} \mathrm{Mg} \mathrm{yr}^{-1}\right)$.

\begin{tabular}{llrrrrr}
\hline & & $\mathrm{CO}$ & $\mathrm{NO}_{x}$ & $\mathrm{HC}$ & $\mathrm{PM}_{2.5}$ & $\mathrm{PM}_{10}$ \\
\hline \multirow{3}{*}{ This study } & Urban & 4.61 & 1.07 & 0.52 & 0.04 & 0.05 \\
& Suburban & 30.61 & 10.98 & 3.58 & 0.45 & 0.50 \\
\hline & Total & 35.22 & 12.05 & 4.10 & 0.49 & 0.55 \\
\hline MEIC-2016 & (Gridded) & 43.56 & 8.45 & 9.26 & 0.46 & 0.47 \\
PRD-2015 & (Gridded) & 28.89 & 6.99 & 4.65 & 0.52 & 0.52 \\
\hline
\end{tabular}

sions, respectively, suggesting that the suburban areas are the dominant contributor to on-road emissions in Guangzhou.

In general, the difference between the amounts of $\mathrm{PM}_{2.5}$ and $\mathrm{PM}_{10}$ was smaller than that for other gaseous emissions among different inventories. This was because the uncertainty in particulate matter emission factors was lower than the corresponding values of the other gaseous emissions, which led to the large difference for the gaseous emissions and the smaller differences for $\mathrm{PM}_{2.5}$ and $\mathrm{PM}_{10}$. For $\mathrm{NO}_{x}$ emissions, however, this study showed a higher $\mathrm{NO}_{x}$ estimate than those in the other two inventories. One of the reasons for the higher $\mathrm{NO}_{x}$ estimate may be the application of the updated LPG bus emission factors in this study. Based on a previous local emission factor study, the $\mathrm{NO}_{x}$ emission fac- tor of an LPG-fueled bus is 1.7 times that of a diesel-fueled bus in Guangzhou (Zhang et al., 2013). The results in Fig. 8 show that the $\mathrm{NO}_{x}$ emissions attributable to buses in urban and suburban areas were $20.5 \%$ and $10.8 \%$ of the total $\mathrm{NO}_{x}$ emissions, respectively, showing that the LPG-fueled buses may be responsible for higher $\mathrm{NO}_{x}$ estimates in this study compared to those in the other two inventories.

As shown in Table 3, the emission contribution of local roads in urban areas is the highest component because of the total length of the local roads, which is 5.4 times and 4.8 times that of highways and arterial roads in urban areas, respectively. Although the total length of the highways is shorter, the traffic volume on the highway is much higher than that on the local roads (Fig. 4), thus causing the highest contribution of emissions from the suburban areas. Moreover, the emission contributions from urban and suburban areas differ on weekdays and weekends. In urban areas, the daily total weekday and weekend emissions are 129.94 and $118.29 \mathrm{Mg} \mathrm{d}^{-1}$ of $\mathrm{CO}, 30.15$ and $27.71 \mathrm{Mg} \mathrm{d}^{-1}$ of $\mathrm{NO}_{x}, 14.74$ and $13.40 \mathrm{Mg} \mathrm{d}^{-1}$ of $\mathrm{HC}$, 1.27 and $1.16 \mathrm{Mg} \mathrm{d}^{-1}$ of $\mathrm{PM}_{2.5}$, and 1.41 and $1.29 \mathrm{Mg} \mathrm{d}^{-1}$ of $\mathrm{PM}_{10}$, respectively. In suburban areas, the total weekday and weekend emissions are 873.97 and $758.41 \mathrm{Mg} \mathrm{d}^{-1}$ of $\mathrm{CO}, 315.10$ and $267.91 \mathrm{Mgd}^{-1}$ of $\mathrm{NO}_{x}, 102.46$ and $88.22 \mathrm{Mg} \mathrm{d}^{-1}$ of $\mathrm{HC}, 13.01$ and $10.98 \mathrm{Mg} \mathrm{d}^{-1}$ of $\mathrm{PM}_{2.5}$, and 14.45 and $12.19 \mathrm{Mg} \mathrm{d}^{-1}$ of $\mathrm{PM}_{10}$, respectively. The total respective emissions of $\mathrm{CO}, \mathrm{NO}_{x}, \mathrm{HC}, \mathrm{PM}_{2.5}$, and $\mathrm{PM}_{10}$ on a weekday are $114.5 \%, 116.8 \%, 115.3 \%, 117.6 \%$, and $117.7 \%$ of the values on a weekend, respectively.

\subsubsection{Spatial distribution of emissions}

Due to the vehicular activities, the spatial distribution of onroad emissions was consistent with the structure of the street network. For a better description of this spatial distribution, the emissions were mapped onto a $1 \mathrm{~km}$ resolution fishnet pattern and the total emissions of one grid cell were the sum of all on-road emissions from within the same grid cell. The spatial distribution of each pollutant is shown in Fig. 9. Overall, the high-value grid cells were generally located along the highways. In suburban areas, high-value areas located away from the highways and arterial roads normally denoted suburban town centers that had more local roads and higher traffic volume density. In urban areas, the high-value areas were more closely related to the densities of the urban local roads. The emission hotspots were less prominent in urban areas than in suburban areas due to the strict traffic control policies in urban area. The spatial distribution indicated that the next on-road emissions control policy should pay more attention to the control of vehicles in suburban areas.

Moreover, the spatial distributions of these three emission inventories were compared in this study. Figure 10 shows the distributions of $\mathrm{CO}$ from the three different inventories. The results of both MEIC-2016 and PRD-2015 showed the urban areas as emission hotspots. However, the results from 
(a)

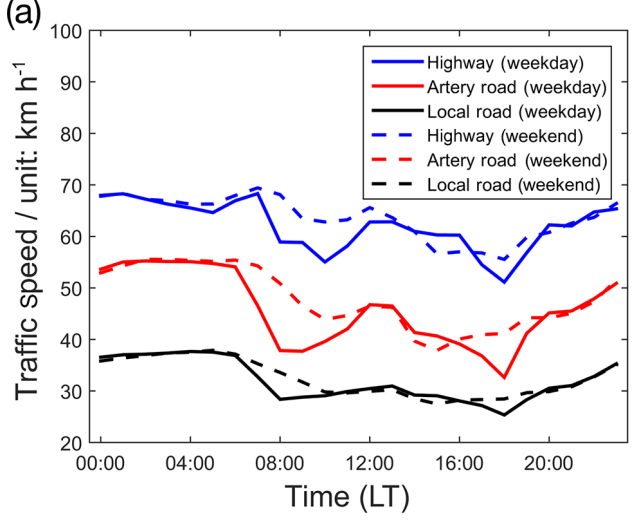

(c)

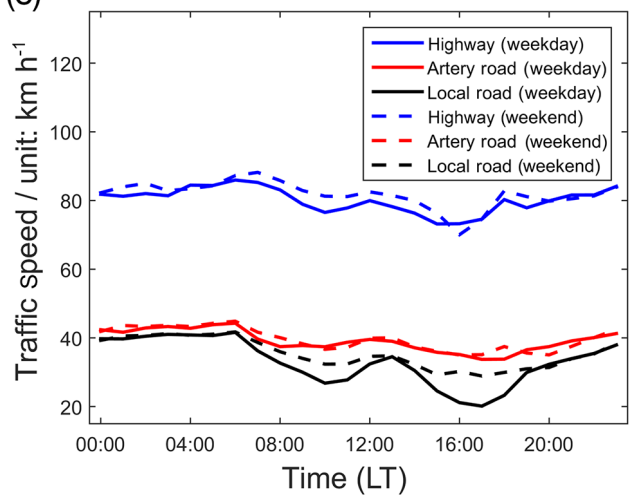

(b)

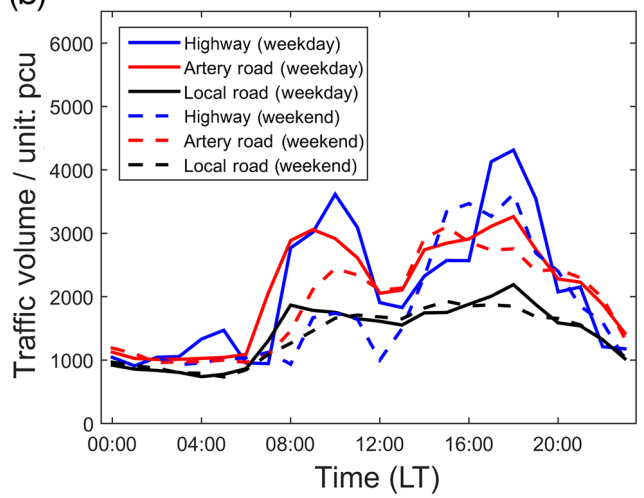

(d)

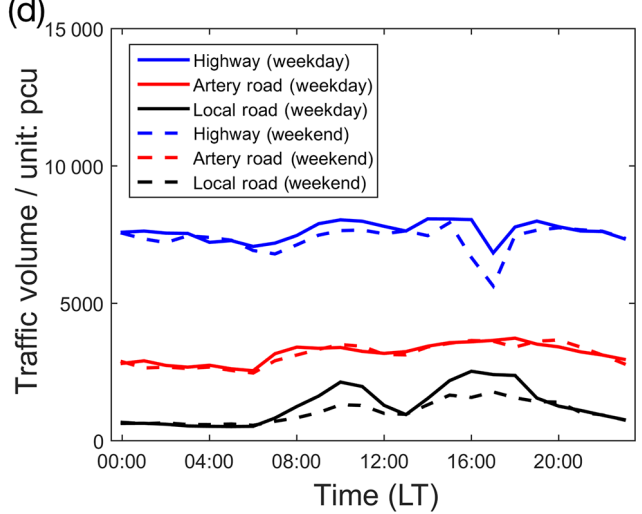

Figure 4. Diurnal variation in average traffic speed and traffic volume in $(\mathbf{a}, \mathbf{b})$ urban area and $(\mathbf{c}, \mathbf{d})$ suburban area during weekday and weekend.

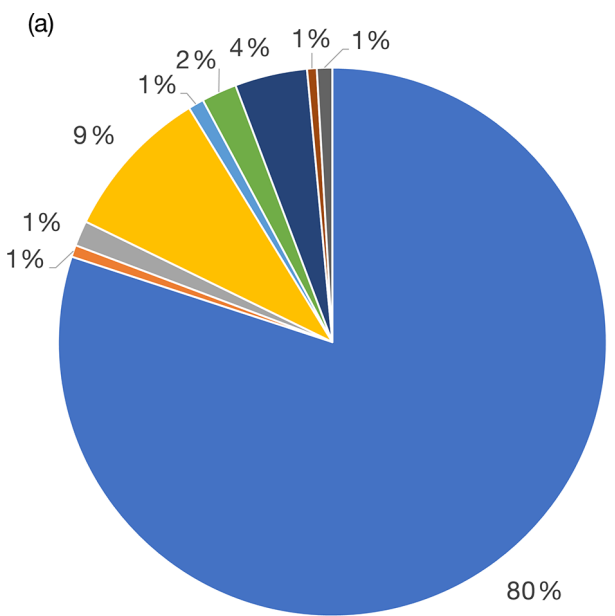

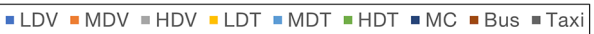

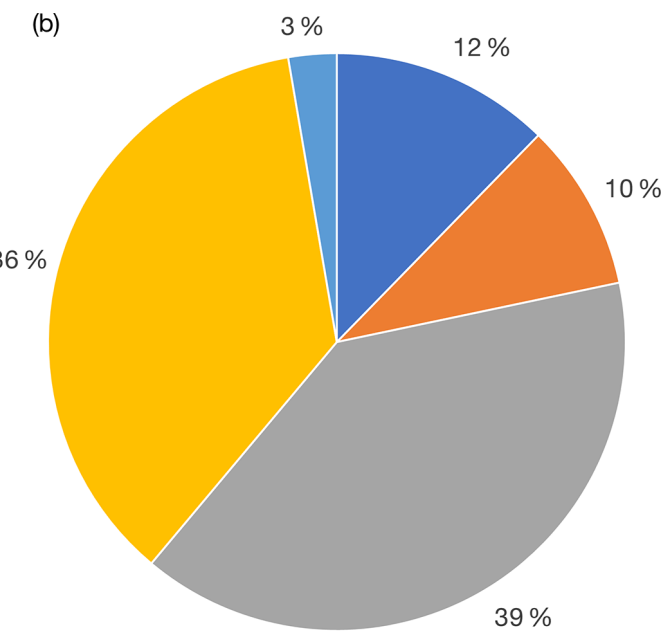

-CHINA I $\approx$ CHINA II $\approx$ CHINA III $\approx$ CHINA IV $\approx$ CHINA V

Figure 5. The percentage of (a) vehicle classification and (b) emission standard. 
Table 3. Daily emissions on different road types in urban and suburban areas (unit: $\mathrm{Mgd}^{-1}$ ).

\begin{tabular}{|c|c|c|c|c|c|c|c|c|}
\hline & & Road type & Length (km) & $\mathrm{CO}$ & $\mathrm{NO}_{x}$ & $\mathrm{HC}$ & $\mathrm{PM}_{2.5}$ & $\mathrm{PM}_{10}$ \\
\hline \multirow[t]{6}{*}{ Weekday } & urban & highway & 301.87 & 9.71 & 3.15 & 1.02 & 0.11 & 0.12 \\
\hline & & artery & 337.19 & 17.24 & 4.95 & 1.88 & 0.19 & 0.21 \\
\hline & & local & 1629.92 & 102.99 & 22.05 & 11.84 & 0.97 & 1.08 \\
\hline & suburban & highway & 2316.73 & 417.49 & 168.29 & 45.51 & 6.50 & 7.22 \\
\hline & & artery & 747.63 & 61.12 & 26.54 & 7.24 & 1.11 & 1.23 \\
\hline & & local & 8867.69 & 395.36 & 120.27 & 49.71 & 5.40 & 6.00 \\
\hline \multirow[t]{6}{*}{ Weekend } & urban & highway & 301.87 & 7.47 & 2.34 & 0.79 & 0.08 & 0.09 \\
\hline & & artery & 337.19 & 13.20 & 4.23 & 1.40 & 0.15 & 0.17 \\
\hline & & local & 1629.92 & 97.62 & 21.14 & 11.21 & 0.93 & 1.03 \\
\hline & suburban & highway & 2316.73 & 428.30 & 156.78 & 47.14 & 6.07 & 6.74 \\
\hline & & artery & 747.63 & 59.20 & 26.56 & 6.99 & 1.10 & 1.22 \\
\hline & & local & 8867.69 & 270.91 & 84.57 & 34.09 & 3.81 & 4.23 \\
\hline
\end{tabular}

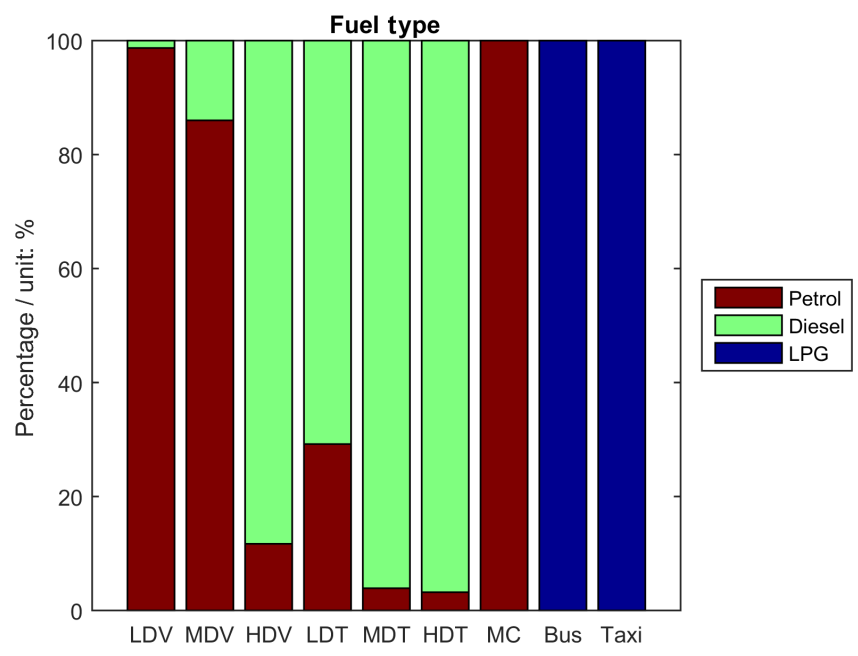

Figure 6. Fuel type percentage of each vehicle classification.

the ROE model were much lower for such areas. This may be due to the fact that the ROE model considers the traffic control policies, while the other two inventories do not. In suburban town centers, especially in the eastern and southern parts of Guangzhou, all three inventories showed the same results, namely that these areas were large contributors of on-road emissions. Notably, highways and arterial roads also contributed high emissions in all three inventories.

\subsubsection{Emission contributions of vehicles by their classification}

The emission contributions of different vehicle classifications in the urban and suburban areas are shown in Fig. 8. As LDVs accounted for the largest number, their emission contribution comprised the dominant proportion of total emissions in urban areas for each pollutant. The contribution percentages of $\mathrm{CO}, \mathrm{HC}, \mathrm{NO}_{x}, \mathrm{PM}_{2.5}$, and $\mathrm{PM}_{10}$ were $80.9 \%$, $84.1 \%, 26.4 \%, 38.3 \%$, and $38.2 \%$, respectively. HDVs were the second largest contributor to on-road emissions, the relevant percentages being $5.8 \%, 2.9 \%, 30.3 \%, 35.2 \%$, and $35.2 \%$ for $\mathrm{CO}, \mathrm{HC}, \mathrm{NO}_{x}, \mathrm{PM}_{2.5}$, and $\mathrm{PM}_{10}$, respectively. As for the buses, except for the contribution of $\mathrm{NO}_{x}$ which accounted for $20.5 \%$ of the total emissions mentioned above, the proportions of the other pollutants were less than $2 \%$ because of the use of LPG as fuel. In the case of trucks, the total contribution of LDTs, MDTs, and HDTs were 10.3\%, $9.3 \%$, $21.2 \%, 23.3 \%$, and $23.3 \%$ for $\mathrm{CO}, \mathrm{HC}, \mathrm{NO}_{x}, \mathrm{PM}_{2.5}$, and $\mathrm{PM}_{10}$, respectively, considering the traffic control policies in the urban areas. The contribution of taxis was less than $1 \%$ because of the small number of taxis and their use of LPG. In suburban areas, the LDVs were the dominant contributor of $\mathrm{CO}$ and $\mathrm{HC}$ emissions because of their high numbers. For $\mathrm{NO}_{x}, \mathrm{PM}_{2.5}$, and $\mathrm{PM}_{10}$, however, the HDT provided the largest contribution at $36.5 \%, 43.2 \%$, and $43.3 \%$, respectively. Moreover, LDVs, HDVs, and buses were important contributors of $\mathrm{NO}_{x}$ at $19.4 \%, 17.4 \%$, and $10.8 \%$, respectively. Regarding particulate matter, the respective percentages of emissions (for both $\mathrm{PM}_{2.5}$ and $\mathrm{PM}_{10}$ ) owing to LDVs, HDVs, and LDTs were $19.7 \%, 20.5 \%$, and $9.0 \%$, suggesting that these vehicles were also important sources of both $\mathrm{PM}_{2.5}$ and $\mathrm{PM}_{10}$.

\subsection{Application of the ROE model's results to the street-level air quality model}

\subsubsection{Modeling performance in Guangzhou urban area}

During the simulation period, the model results were evaluated for the TYX observation site located within the street network. The on-road emissions were provided by the ROE model, as discussed previously. Street segments to which high $\mathrm{NO}_{x}$ emission values were attributed were also responsible for high HC emissions because of the positive relationship between traffic volume and on-road emissions as shown in Fig. 11. 
(a)

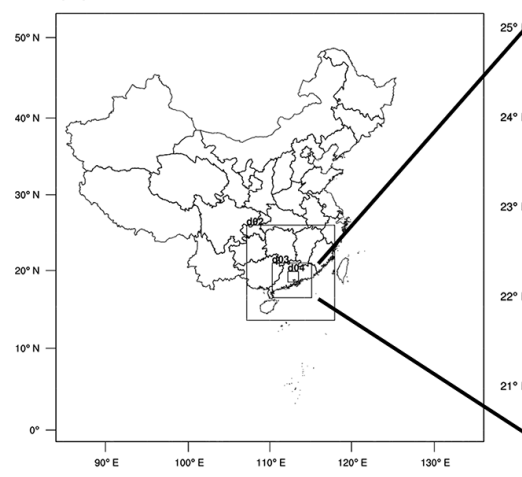

(b)

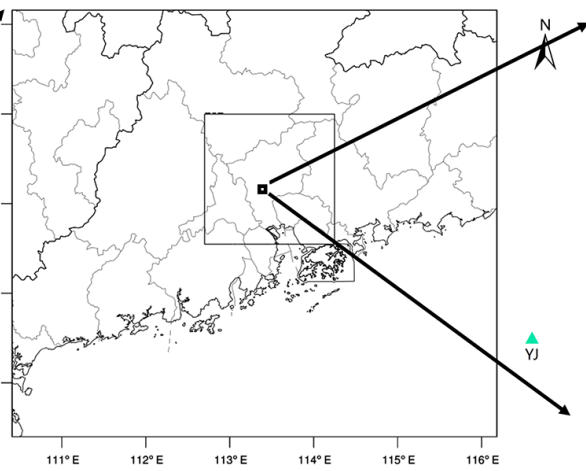

(c)

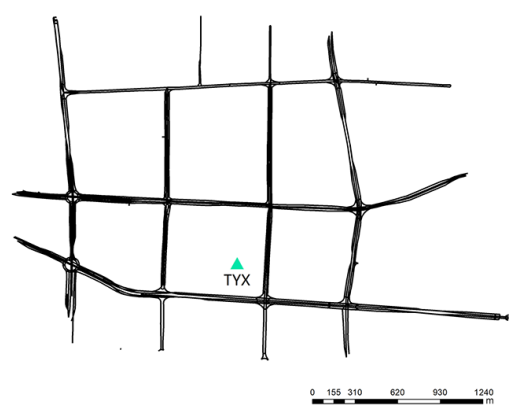

Figure 7. Simulation domain from regional scale to street-level scale: (a) four times nested simulation for WRF; (b) domains 3 and 4 covering the Pearl River Delta region and Guangzhou city, the innermost box corresponds to the Tianhe District; (c) 31 street segments and two observation sites (triangles) within the MUNICH study domain.
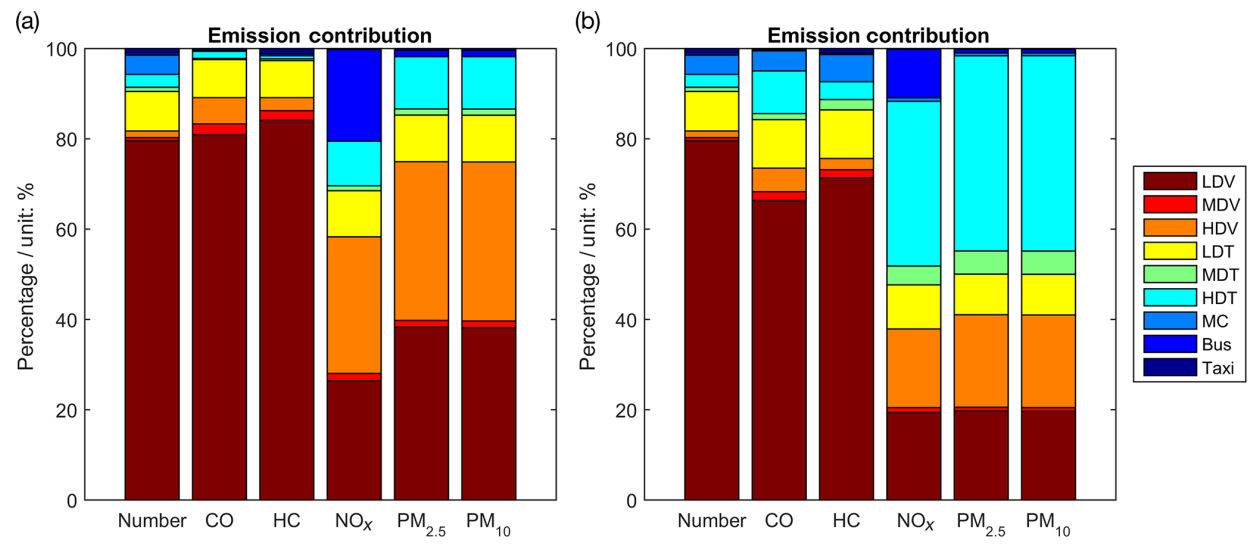

Figure 8. Emission contribution of each vehicle classification in (a) urban area and (b) suburban area.

The time series for the simulated $\mathrm{NO}_{2}$ and $\mathrm{O}_{3}$ concentrations within the street network were compared with the observed concentrations (Fig. 12). As the results show, daytime $\mathrm{NO}_{2}$ concentrations were overestimated while nighttime concentrations were underestimated during the simulation period. The $\mathrm{O}_{3}$ concentrations, however, were underpredicted during daytime and overpredicted at nighttime. Several modeling sensitivity cases were analyzed to identify what factors may have affected the model simulation. The sensitivity analysis results are provided in the Supplement Sect. S3. Typically, the overestimated background concentrations of $\mathrm{NO}_{2}$ and $\mathrm{O}_{3}$ were attributed as the reason for the overprediction of the daytime $\mathrm{NO}_{2}$ and nighttime $\mathrm{O}_{3}$ concentrations, respectively. The underestimated $\mathrm{NO}$ titration was the other main reason for the overprediction of $\mathrm{O}_{3}$ and the underprediction of $\mathrm{NO}_{2}$ concentrations at night. Due to the only consideration of on-road emission in the simulation street network, daytime $\mathrm{O}_{3}$ concentrations were underpredicted in the results.

Moreover, the performance statistics for $\mathrm{NO}_{2}$ and $\mathrm{O}_{3}$ are shown in Table 4. Here, the statistical measures of the ob- servation (OBS) mean, simulation (SIM) mean, mean bias (MB), normalized mean bias (NMB), normalized mean error (NME), mean relative bias (MRB), mean relative error (MRE), root-mean-squared error (RMSE), and the correlation coefficient (CORR) were used to validate the model. The $\mathrm{NMB}, \mathrm{NME}$, and CORR values of $\mathrm{NO}_{2}$ and $\mathrm{O}_{3}$ in this study were within the recommended ranges in the MEP Technical Guide for Air Quality Model Selection (MEP, 2012). These recommended values were $-40 \%<\mathrm{NMB}<50 \%$, NME $<$ $80 \%$, and $R^{2}>0.3$ for $\mathrm{NO}_{2}$ and $-15 \%<\mathrm{NMB}<15 \%$, $\mathrm{NME}<35 \%$, and $R^{2}>0.4$ for $\mathrm{O}_{3}$. Additionally, the values obtained in this study fell within the range of those reported by other modeling studies in Guangzhou; the NMB, NME, and RMSE values for simulated urban $\mathrm{NO}_{2}$ in Guangzhou ranged from $-27.5 \%$ to $-6 \%, 29.2 \%$ to $53.0 \%$, and 16 to 37.3 , respectively, and the corresponding ranges for $\mathrm{O}_{3}$ were from $-21.2 \%$ to $20.0 \%, 38.2 \%$ to $98 \%$, and 9.4 to 40.1 (Che et al., 2011; Fan et al., 2015; Wang et al., 2016). Overall, the model showed good simulation performance and can be applied to future studies investigating the impact of onroad vehicles on air quality. 


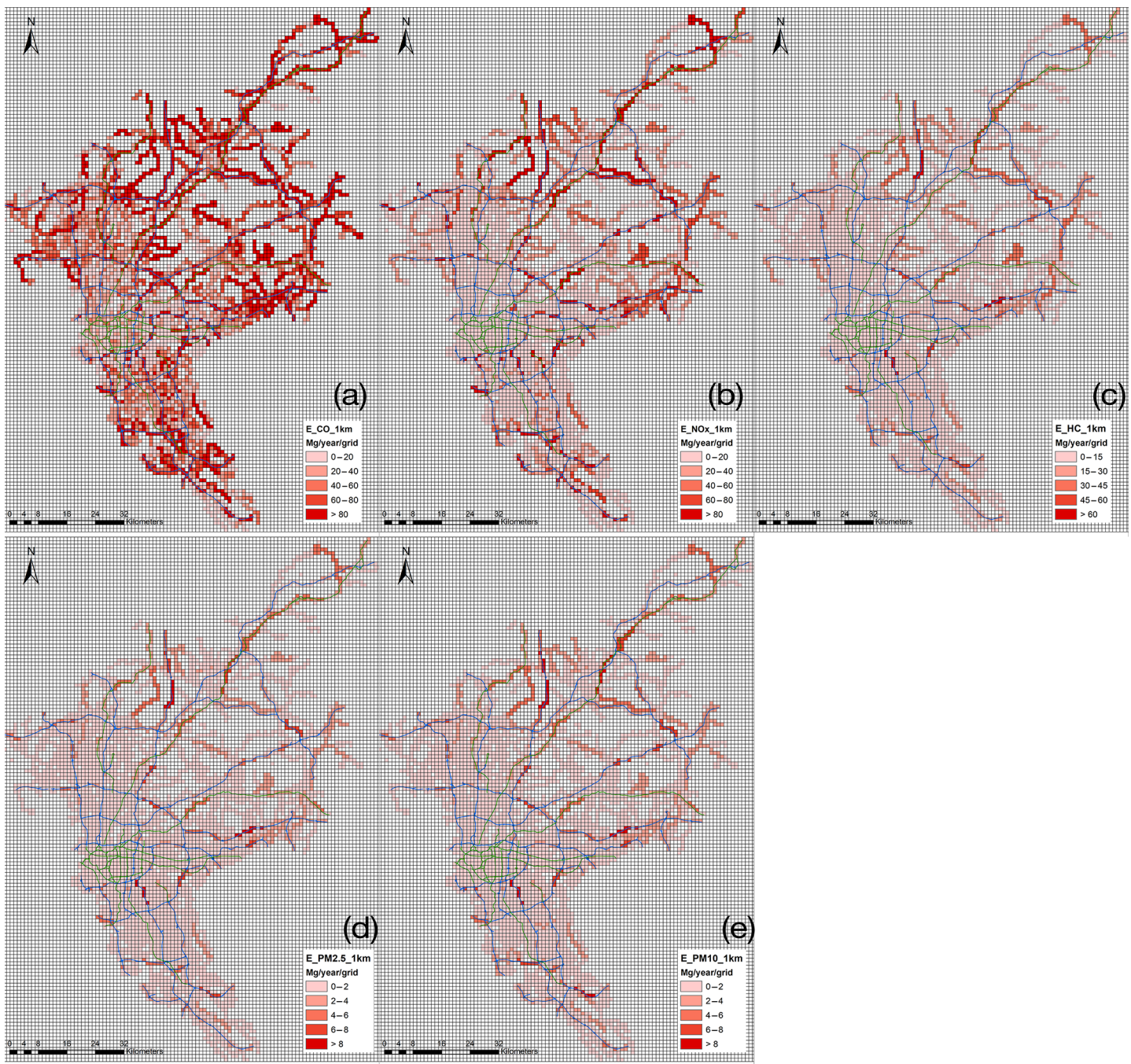

Figure 9. Spatial distribution of (a) $\mathrm{CO}$, (b) $\mathrm{NO}_{x}$, (c) $\mathrm{HC}$, (d) $\mathrm{PM}_{2.5}$, and (e) $\mathrm{PM}_{10}$ from the on-road emissions in Guangzhou (blue lines: highways; green lines: arterial roads; local roads are not shown).
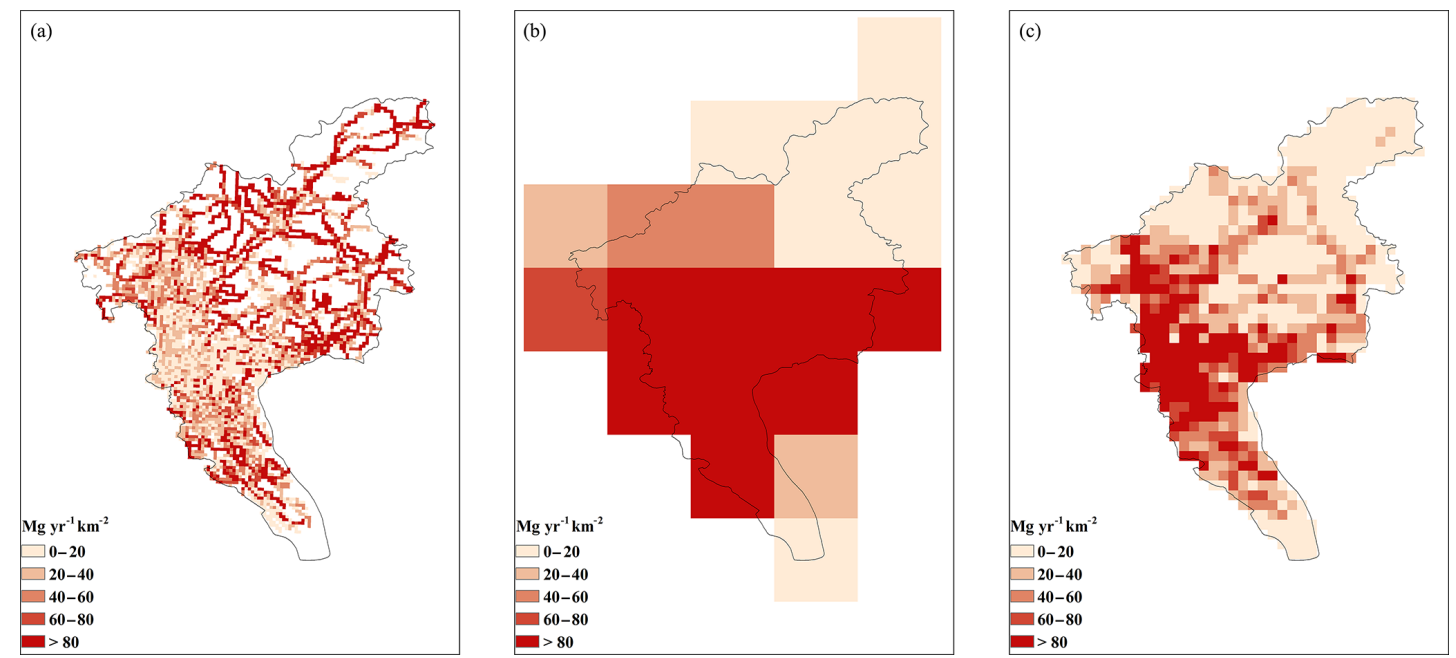

Figure 10. Spatial distribution of CO from (a) ROE model, (b) MEIC-2016, and (c) PRD-2015 in Guangzhou. 
(a)

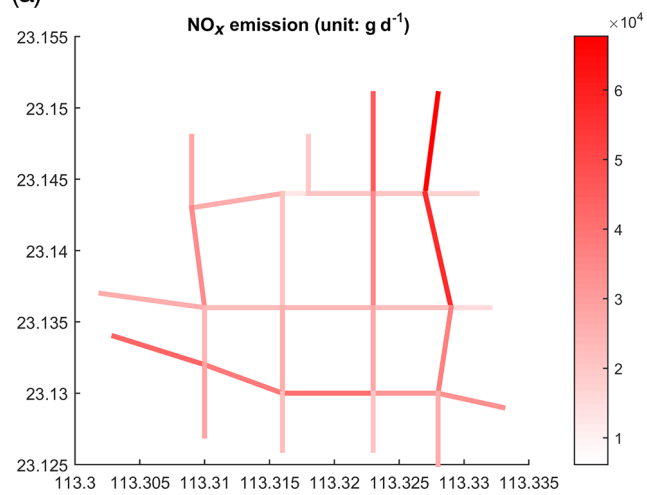

(b)

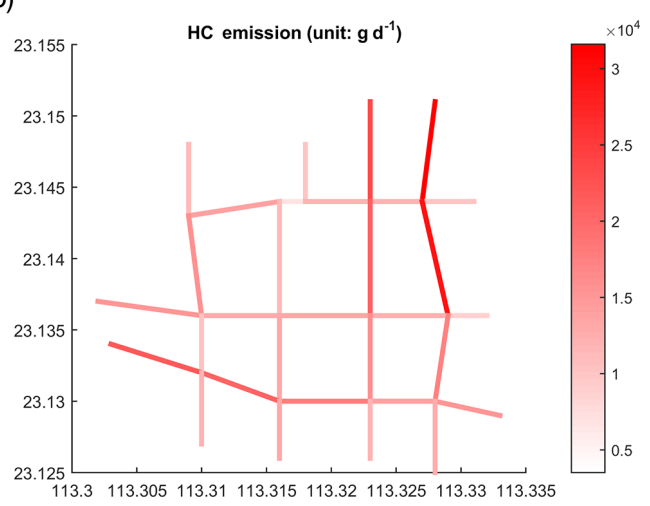

Figure 11. The spatial distribution of weekday (a) $\mathrm{NO}_{x}$ and (b) $\mathrm{HC}$ emissions in the simulated street network.

(a)

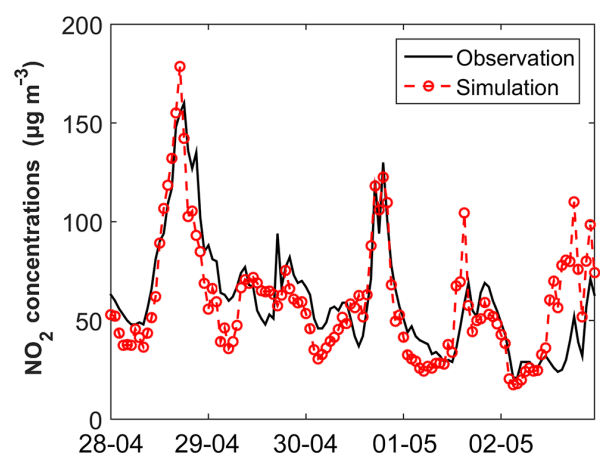

(b)

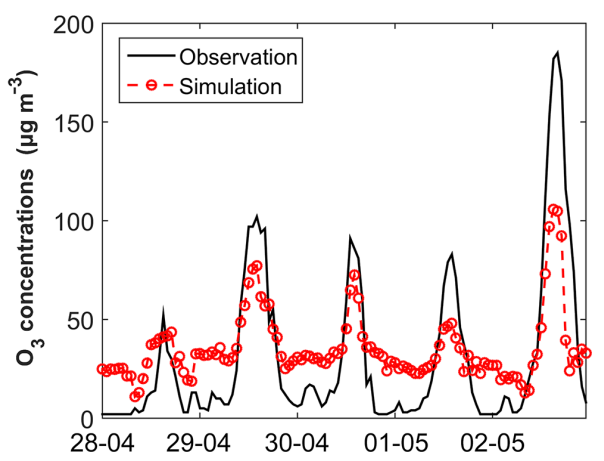

Figure 12. Time series of (a) $\mathrm{NO}_{2}$ and (b) $\mathrm{O}_{3}$ during the simulation period. (solid black line: observation; dashed red line: simulation).

\subsubsection{Impact of traffic volume variations on air quality}

To investigate how traffic volume change affects air quality at the street level, a Chinese national holiday was chosen as the target simulation period for the modeling. Figure 13 shows the diurnal variation in the traffic volume during the national holiday, normal weekday, and normal weekend before and after the holiday in the simulation street network. On the normal weekday, two typical rush hour trends appeared during the 08:00-10:00 and 17:00-19:00 periods (although 28 April was a Saturday, it was a normal workday to compensate for the holiday). For the normal weekend and the national holiday, the peak in traffic volume was noted between 14:00 and 16:00 and no rush hour peak occurred on these days. At nighttime, not much difference was noted for the traffic volumes on the normal weekday, normal weekend, and national holiday, especially after midnight. However, the higher traffic volume between 21:00 and 23:00 on 28 April at night may have been caused by people traveling out of the city before the national holiday (e.g., returning home across the city or traveling to other places).

Three sensitivity cases were carried out to study the impact of traffic volume change on the air quality in urban areas: (1) in the national holiday case, wherein the on-road emis-

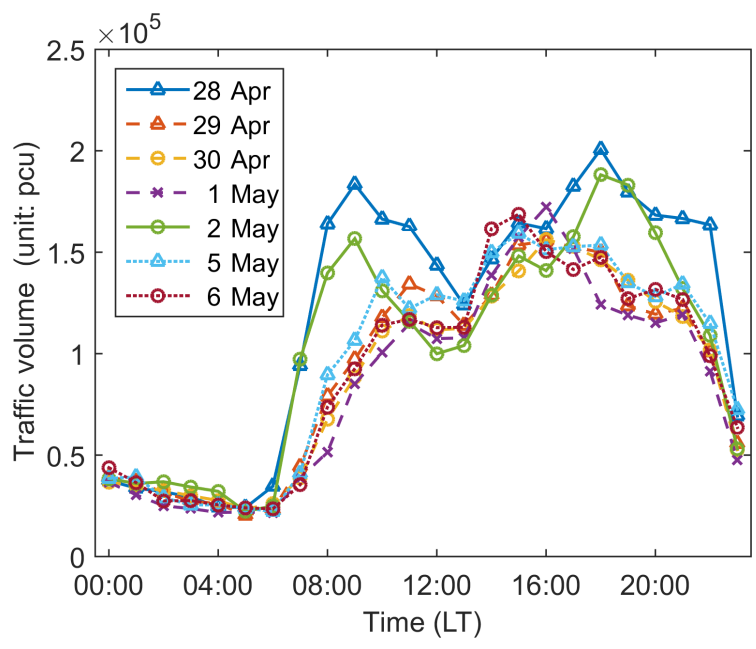

Figure 13. The diurnal variation in the total traffic volume in the simulation street network (solid line: normal weekday; dashed line: national holiday; dotted line: normal weekend).

sions between 29 April and 1 May were regarded as the original emissions during the simulation period (this represents the base case); (2) in the normal weekday case, diurnal on- 
Table 4. The performance statistics for $\mathrm{NO}_{2}$ and $\mathrm{O}_{3}$ in modeling (unit: $\mu \mathrm{g} \mathrm{m}^{-3}$ ).

\begin{tabular}{lrrrrrrrrr}
\hline & \multicolumn{2}{c}{ Mean } & & & & & & & \\
\cline { 2 - 5 } & OBS $^{\mathrm{a}}$ & SIM $^{\mathrm{b}}$ & $\mathrm{MB}^{\mathrm{c}}$ & $\mathrm{NMB}^{\mathrm{d}}$ & $\mathrm{NME}^{\mathrm{e}}$ & $\mathrm{MRB}^{\mathrm{f}}$ & MRE $^{\mathrm{g}}$ & RMSE $^{\mathrm{h}}$ & CORR $^{\mathrm{i}}$ \\
\hline $\mathrm{NO}_{2}$ & 30.8 & 35.4 & 4.7 & $15.2 \%$ & $68.8 \%$ & $3.0 \%$ & $3.2 \%$ & 25.7 & 0.90 \\
$\mathrm{O}_{3}$ & 60.9 & 59.3 & -1.6 & $-2.7 \%$ & $24.3 \%$ & $<0.1 \%$ & $0.3 \%$ & 18.7 & 0.80 \\
\hline
\end{tabular}

${ }^{a}$ OBS (observation). ${ }^{b}$ SIM (simulation). ${ }^{c}$ MB (mean bias). ${ }^{d}$ NMB (normalized mean bias). ${ }^{e}$ NME (normalized mean error).

${ }^{\mathrm{f}}$ MRB (mean relative bias). ${ }^{\mathrm{g}}$ MRE (mean relative error). ${ }^{\mathrm{h}}$ RMSE (root-mean-squared error). ${ }^{\mathrm{i}}$ CORR (correlation coefficient).

road emissions for three national holidays were replaced by the emissions of 28 April; and (3) in the normal weekend case, the national holiday period emissions were replaced by the diurnal on-road emissions of 5 May. The diurnal variations in $\mathrm{NO}_{x}$ and $\mathrm{O}_{3}$ in the three cases are shown in Fig. 14. During 00:00-05:00, because of similar traffic volume, there were no large differences in the $\mathrm{NO}_{x}$ and $\mathrm{O}_{3}$ concentrations during this time. Due to the morning rush hour, the $\mathrm{NO}_{x}$ concentrations for the normal weekday case were much higher than those for the national holiday case in the morning. As shown in Table 5, the $\mathrm{NO}_{x}$ concentrations were $12.0 \%-$ $26.5 \%$ higher for the normal weekday case during this time. In the normal weekend case too, the $\mathrm{NO}_{x}$ concentrations simultaneously increased by $9.1 \%$ compared to those on the national holiday in the morning. This increase was caused by people traveling for normal weekend engagements. In the afternoon, however, the difference between the $\mathrm{NO}_{x}$ concentrations was less than $10 \%$ due to the rising traffic volume on the national holiday. During the evening rush hour, although the traffic volume on the normal weekday was 1.3 times that on the national holiday, the maximum difference between the $\mathrm{NO}_{x}$ concentrations was only $7.3 \%$. This shows that the variations in $\mathrm{NO}_{x}$ concentrations were affected to a greater extent by the background concentrations (i.e., boundary conditions) in the evening.

Compared with the national holiday case, the $\mathrm{O}_{3}$ concentrations were much lower in the normal weekday case. In the afternoon, as shown in Table 6, when photochemical reactions are more prevalent, the national holiday $\mathrm{O}_{3}$ concentrations exceeded those on normal weekdays and weekends by $13.9 \%$ and $10.6 \%$, respectively. This is because the simulation street network in the urban areas is in the VOC-sensitive (volatile organic compound) regime (Ye et al., 2016). The $\mathrm{O}_{3}$ concentrations were positively correlated with the VOC emissions. As the $\mathrm{NO}_{x}$ emissions were higher than the VOC emissions, the reduction in the $\mathrm{NO}_{x}$ emissions was also much higher than in the VOC emissions when the number of vehicles decreased on the national holiday. The larger $\mathrm{NO}_{x}$ emission reduction led to a higher VOCs-to- $\mathrm{NO}_{x}$ emission ratio, which resulted in a higher $\mathrm{O}_{3}$ concentration during the national holiday (Sanford and He, 2002).

\section{Discussion and conclusions}

Using real-world traffic information, the Real-time On-road Emission (ROE v1.0) model can provide real-time and highresolution emission inventories for regional or street-level air quality models in China. The results show that the ROE model can simulate the emissions of $\mathrm{CO}, \mathrm{NO}_{x}, \mathrm{HC}, \mathrm{PM}_{2.5}$, $\mathrm{PM}_{10}$, and any other pollutant provided the relevant emission factors are included in the model. (This aspect will be updated in subsequent releases.) As it uses the bottomup method, the ROE model facilitates the calculation of the emissions in each street segment.

In this study, the traffic information of Guangzhou was obtained from the Gaode Map, the data for which are collected from map users while they are driving. The geographic and speed information were sourced from the map users' GPS devices and can be used through the map API. Using the ROE model and fully considering the traffic control policies of Guangzhou city, the annual total on-road emissions of $\mathrm{CO}, \mathrm{NO}_{x}, \mathrm{HC}, \mathrm{PM}_{2.5}$, and $\mathrm{PM}_{10}$ were modeled to be $35.22 \times 10^{4}, 12.05 \times 10^{4}, 4.10 \times 10^{4}, 0.49 \times 10^{4}$, and $0.55 \times 10^{4} \mathrm{Mg} \mathrm{yr}^{-1}$, respectively. Spatial distribution analysis showed that hotspots of on-road emissions were situated along the highways and suburban town centers. The comparison of spatial distribution between the ROE model's results and those of two other inventories showed that the ROE model provided lower urban emissions as it considered the traffic control polices. However, it should be noted that this comparison was only preliminary. The spatial resolutions of the three inventories are inconsistent in this study. Moreover, due to the lack of temporal information about the other two emission inventories, a comparison of the temporal difference could not be conducted. Future studies should focus on improving the accuracy of such comparisons.

Owing to the number of vehicles and their respective distributions, LDVs constituted the dominant source of on-road emissions in Guangzhou. In suburban areas, however, HDTs were the highest contributors of $\mathrm{NO}_{x}, \mathrm{PM}_{2.5}$, and $\mathrm{PM}_{10}$. Daily emissions of $\mathrm{CO}, \mathrm{NO}_{x}, \mathrm{HC}, \mathrm{PM}_{2.5}$, and $\mathrm{PM}_{10}$ on a weekday were found to be $14.5 \%, 16.8 \%, 15.3 \%, 17.6 \%$, and $17.7 \%$ higher than the daily emissions on a weekend, respectively. However, due to the lack of street-level vehicle fleet information, this study applied a city-level average uniform percentage for every street segment. This may increase 
Table 5. Daytime percentage difference of $\mathrm{NO}_{x}$ compared to national holiday case.

\begin{tabular}{|c|c|c|c|c|c|c|c|c|c|c|c|c|c|c|c|}
\hline Time & 06:00 & 07:00 & 08:00 & 09:00 & 10:00 & 11:00 & $12: 00$ & 13:00 & $14: 00$ & $15: 00$ & $16: 00$ & $17: 00$ & $18: 00$ & 19:00 & 20:00 \\
\hline Normal weekday & 12.7 & 21.7 & 16.8 & 26.5 & 14.7 & 12.0 & 4.9 & 0.6 & 8.6 & 2.2 & 0.7 & 0.2 & 7.3 & 5.9 & 7.1 \\
\hline Normal weekend & -4.4 & 0.1 & 9.1 & 6.7 & 0.2 & 7.0 & 1.2 & 2.6 & 6.2 & 0.8 & -0.6 & -0.9 & 2.1 & -5.7 & 4.9 \\
\hline
\end{tabular}

Table 6. Daytime percentage difference of $\mathrm{O}_{3}$ compared to national holiday case.

\begin{tabular}{|c|c|c|c|c|c|c|c|c|c|c|c|c|c|c|c|}
\hline Time & 06:00 & 07:00 & 08:00 & 09:00 & 10:00 & 11:00 & $12: 00$ & $13: 00$ & $14: 00$ & $15: 00$ & $16: 00$ & $17: 00$ & 18:00 & 19:00 & 20:00 \\
\hline Normal weekend & 2.9 & 6.3 & -2.6 & -4.9 & -15.0 & 0.5 & -4.0 & -1.6 & -5.7 & -10.6 & -0.4 & 12.4 & -15.3 & -0.1 & 3.7 \\
\hline
\end{tabular}

(a)

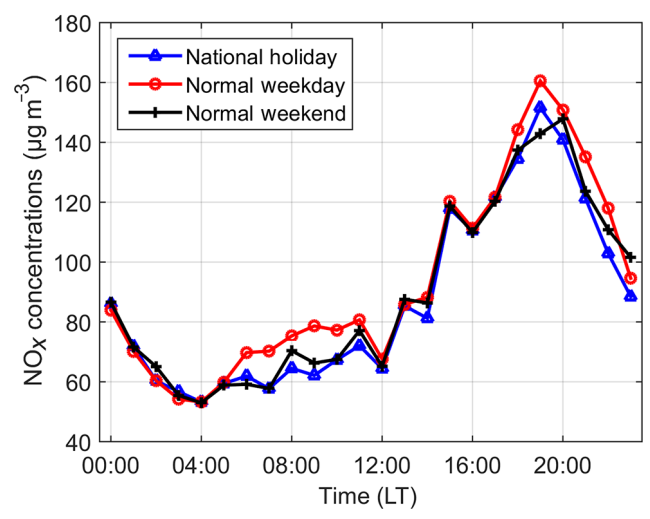

(b)

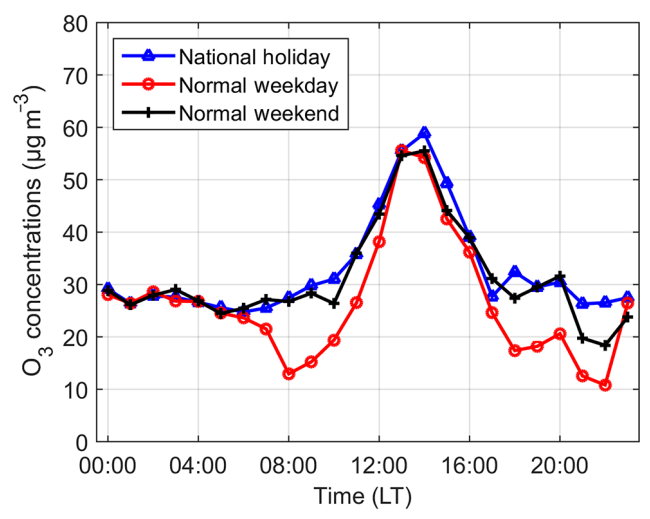

Figure 14. The (a) $\mathrm{NO}_{x}$ and (b) $\mathrm{O}_{3}$ diurnal variation in different sensitivity cases in the simulation street network.

the uncertainty in the inventory but this aspect can be improved upon, provided additional data become available in the future. Given the high spatial and temporal resolutions of the emission inventory of the ROE model, three sensitivity cases were analyzed to study the effect of vehicular on-road emissions on urban street-level air quality. On a national holiday, $\mathrm{NO}_{x}$ concentrations were $12.0 \%-26.5 \%$ less than those on a normal weekday as no morning rush hours occurred on holidays. Moreover, compared with the normal weekend, the $\mathrm{NO}_{x}$ concentrations on a national holiday also show a decrease of $9.1 \%$ in the peak value in the morning. However, the reduction in the $\mathrm{NO}_{x}$ concentrations in the afternoon was smaller than that in the morning, suggesting that the transportation of $\mathrm{NO}_{x}$ from the surrounding areas was the main reason for the variation in the afternoon $\mathrm{NO}_{x}$ concentrations. In addition, as the simulation street network lies in the VOCsensitive regime, the lower traffic on a national holiday and a normal weekend caused the $\mathrm{NO}_{x}$ and VOC emissions to be lower than those on a normal weekday. However, the reductions in $\mathrm{NO}_{x}$ were higher than the decrease in VOC emissions, which led to a higher VOC-to- $\mathrm{NO}_{x}$ emission ratio and $\mathrm{O}_{3}$ concentrations on holidays and normal weekends. In this study, only 31 main street segments were selected to study the impact of a holiday on air quality in a certain urban area of Guangzhou. Additional investigations are required to un- derstand the variations in street-level air quality in urban or suburban areas of a megacity. The results of the ROE model showed that the suburban town centers of Guangzhou served as emission hotspots. These areas had relatively higher emissions than the other suburban areas and less stringent control policies than the urban area, which suffers from more serious air quality problems.

In general, the ROE model could provide a high-resolution on-road emission inventory when the real-time traffic information and emission factors were fed into the model. It is worth noting that the ROE model is highly dependent on the ITS traffic data. For economically underdeveloped cities, this aspect may pose a barrier against the use of the ROE model. In addition, China is promoting the CHINA VI emission standards for on-road vehicles. The ROE model only considers Pre-CHINA I to CHINA V currently. Thus, the model will be updated in the near future to include the CHINA VI emission standards.

Recently studies had shown that traffic forecasting models are effective within cities (Min et al., 2009; Cortez et al., 2012; Vlahogianni et al., 2014). These models allow one to obtain predicted traffic-based on-road emissions. Combined with the meteorological forecasting systems and regional air quality forecasting systems, which provide the meteorological and background concentration predictions, respectively, 
street-level air quality models could be used for street-level air quality forecasting as well.

In summary, the newly developed ROE model was confirmed to be effective for analyzing real-time city-scale traffic emissions and performing high-resolution air quality assessments in the street networks of Guangzhou city. The methodologies presented in this work can be further extended to more typical cities, urban districts in China, or other countries.

Code availability. The python source code of the ROE v1.0 model and examples are available on GitHub (https:/github.com/vnuni23/ ROE, last access: 2 September 2019) and Zenodo (https://doi.org/ 10.5281/zenodo.3264859, Wu, 2019). More information and help are also available by contacting the authors.

Supplement. The supplement related to this article is available online at: https://doi.org/10.5194/gmd-13-23-2020-supplement.

Author contributions. LW and XW designed the experiments. LW developed the model code and performed the simulations. MC organized and visualized the data. JZ collected and organized the observational data. $\mathrm{LW}$ and $\mathrm{JH}$ prepared the article with contributions from all coauthors. LW organized the results of model sensitivity cases. XW and MS proposed revision suggestions for the article.

Competing interests. The authors declare that they have no conflict of interest.

Acknowledgements. We acknowledge the technical support and computational time from the Tianhe-2 platform at the National Supercomputer Center in Guangzhou. We also thank Yang Zhang and Youngseob Kim for their helpful advice on the street-level air quality model.

Financial support. This research has been supported by the National Key Research and Development Program of China (grant no. 2016YFC0202206), the National Nature Science Fund for Distinguished Young Scholars (grant no. 41425020), the State Key Program of National Natural Science Foundation of China (grant no. 91644215), and the National Natural Science FoundationOutstanding Youth Foundation (grant no. 41622502).

Review statement. This paper was edited by David Topping and reviewed by two anonymous referees.

\section{References}

An, X., Hou, Q., Li, N., and Zhai, S.: Assessment of human exposure level to $\mathrm{PM}_{10}$ in China, Atmos. Environ., 70, 376-386, https://doi.org/10.1016/j.atmosenv.2013.01.017, 2013.

Ashie, Y. and Kono, T.: Urban-scale CFD analysis in support of a climate-sensitive design for the Tokyo Bay area, Int. J. Climatol., 31, 174-188, https://doi.org/10.1002/joc.2226, 2011.

Britter, R. E. and Hanna, S. R.: Flow and dispersion in urban areas, Annu. Rev. Fluid Mech., 35, 469-496, https://doi.org/10.1146/annurev.fluid.35.101101.161147, 2003.

Cai, H. and Xie, S. D.: Estimation of vehicular emission inventories in China from 1980 to 2005, Atmos. Environ., 41, 8963-8979, https://doi.org/10.1016/j.atmosenv.2007.08.019, 2007.

Che, W., Zheng, J., Wang, S., Zhong, L., and Lau, A.: Assessment of motor vehicle emission control policies using Model-3/CMAQ model for the Pearl River Delta region, China, Atmos. Environ., 45, 1740-1751, https://doi.org/10.1016/j.atmosenv.2010.12.050, 2011.

Chen, F., Kusaka, H., Bornstein, R., Ching, J., Grimmond, C. S. B., Grossman-Clarke, S., Loridan, T., Manning, K. W., Martilli, A., Miao, S., Sailor, D., Salamanca, F. P., Taha, H., Tewari, M., Wang, X., Wyszogrodzki, A. A., and Zhang, C.: The integrated WRF/urban modelling system: development, evaluation, and applications to urban environmental problems, Int. J. Climatol., 31, 273-288, https://doi.org/10.1002/joc.2158, 2011.

Chen, R., Paristech, P., and Aguil, V.: A sensitivity study of road transportation emissions at metropolitan scale, J. Earth Sci. Geotech. Eng., 7, 151-173, 2017.

Ching, J., Mills, G., Bechtel, B., See, L., Feddema, J., Wang, X., Ren, C., Brorousse, O., Martilli, A., Neophytou, M., Mouzourides, P., Stewart, I., Hanna, A., Ng, E., Foley, M., Alexander, P., Aliaga, D., Niyogi, D., Shreevastava, A., Bhalachandran, P., Masson, V., Hidalgo, J., Fung, J., Andrade, M., Baklanov, A., Dai, W., Milcinski, G., Demuzere, M., Brunsell, N., Pesaresi, M., Miao, S., Mu, Q., Chen, F., and Theeuwesits, N.: WUDAPT: An urban weather, climate, and environmental modeling infrastructure for the anthropocene, B. Am. Meteorol. Soc., 99, 1907-1924, https://doi.org/10.1175/BAMS-D-160236.1, 2018.

Cortez, P., Rio, M., Rocha, M., and Sousa, P.: Multi-scale Internet traffic forecasting using neural networks and time series methods, Expert Syst., 29, 143-155, https://doi.org/10.1111/j.14680394.2010.00568.x, 2012.

Davies, L., Bates, J. W., Bell, J. N. B., James, P. W., and Purvis, O. W.: Diversity and sensitivity of epiphytes to oxides of nitrogen in London, Environ. Pollut., 146, 299-310, https://doi.org/10.1016/j.envpol.2006.03.023, 2007.

Di Sabatino, S., Buccolieri, R., Pulvirenti, B., and Britter, R. E.: Flow and pollutant dispersion in street canyons using FLUENT and ADMS-Urban, Environ. Model. Assess., 13, 369-381, https://doi.org/10.1007/s10666-007-9106-6, 2008.

Dudhia, J.: Numerical Study of Convection Observed during the Winter Monsoon Experiment Using a Mesoscale Two-Dimensional Model, J. Atmos. Sci., 46, 3077-3107, https://doi.org/10.1175/15200469(1989)046<3077:NSOCOD>2.0.CO;2, 1989.

EPA: User's Guide to MOBILE6.1 and MOBILE6.2: Mobile Source Emission Factor Model, EPA420-R-03-010, Washington, DC, USA, 2003. 
Fan, Q., Lan, J., Liu, Y., Wang, X., Chan, P., Hong, Y., Feng, Y., Liu, Y., Zeng, Y., and Liang, G.: Process analysis of regional aerosol pollution during spring in the Pearl River Delta region, China, Atmos. Environ., 122, 829-838, https://doi.org/10.1016/j.atmosenv.2015.09.013, 2015.

Fernando, H. J. S., Zajic, D., Di Sabatino, S., Dimitrova, R., Hedquist, B., and Dallman, A.: Flow, turbulence, and pollutant dispersion in urban atmospheres, Phys. Fluids, 22, 1-20, https://doi.org/10.1063/1.3407662, 2010.

Guangzhou Bureau of Statistics: Guangzhou Statistical Yearbook 2017, Guangzhou, People's Republic of China, 2017.

Guo, H., Zhang, Q., Shi, Y., and Wang, D.: On-road remote sensing measurements and fuel-based motor vehicle emission inventory in Hangzhou, China, Atmos. Environ., 41, 3095-3107, https://doi.org/10.1016/j.atmosenv.2006.11.045, 2007.

Hang, J., Luo, Z., Wang, X., He, L., Wang, B., and Zhu, W.: The influence of street layouts and viaduct settings on daily carbon monoxide exposure and intake fraction in idealized urban canyons, Environ. Pollut., 220, 72-86, https://doi.org/10.1016/j.envpol.2016.09.024, 2017.

Hao, J., He, D., Wu, Y., Fu, L., and He, K.: A study of the emission and concentration distribution of vehicular pollutants in the urban area of Beijing, Atmos. Environ., 34, 453-465, https://doi.org/10.1016/S1352-2310(99)00324-6, 2000.

He, J., Wu, L., Mao, H., Liu, H., Jing, B., Yu, Y., Ren, P., Feng, C., and Liu, X.: Development of a vehicle emission inventory with high temporal-spatial resolution based on NRT traffic data and its impact on air pollution in Beijing - Part 2: Impact of vehicle emission on urban air quality, Atmos. Chem. Phys., 16, 31713184, https://doi.org/10.5194/acp-16-3171-2016, 2016.

He, K., Huo, H. and Zhang, Q.: Urban Air Pollution in China: Current Status, Characteristics, and Progress, J. Allergy Clin. Immun., 27, 397-431, https://doi.org/10.1146/annurev.energy.27.122001.083421, 2002.

Hooper, E., Chapman, L., and Quinn, A.: The impact of precipitation on speed-flow relationships along a UK motorway corridor, Theor. Appl. Climatol., 117, 303-316, https://doi.org/10.1007/s00704-013-0999-5, 2014.

Huang, W., Wei, Y., Guo, J. and Cao, J.: Next-generation innovation and development of intelligent transportation system in China, Sci. China Inform. Sci., 60, 1-11, https://doi.org/10.1007/s11432-017-9182-x, 2017.

Huo, H., Zhang, Q., He, K., Wang, Q., Yao, Z., and Streets, D. G.: High-Resolution Vehicular Emission Inventory Using a LinkBased Method?: A Case Study of Light-Duty Vehicles in Beijing, Environ. Sci. Technol., 43, 2394-2399, 2009.

Ibarra-Espinosa, S., Ynoue, R., O’Sullivan, S., Pebesma, E., Andrade, M. D. F., and Osses, M.: VEIN v0.2.2: an R package for bottom-up vehicular emissions inventories, Geosci. Model Dev., 11, 2209-2229, https://doi.org/10.5194/gmd-112209-2018, 2018.

Jing, B., Wu, L., Mao, H., Gong, S., He, J., Zou, C., Song, G., $\mathrm{Li}, \mathrm{X}$., and $\mathrm{Wu}, \mathrm{Z}$.: Development of a vehicle emission inventory with high temporal-spatial resolution based on NRT traffic data and its impact on air pollution in Beijing - Part 1: Development and evaluation of vehicle emission inventory, Atmos. Chem. Phys., 16, 3161-3170, https://doi.org/10.5194/acp16-3161-2016, 2016.
Kain, J. S.: The Kain-Fritsch Convective Parameterization: An Update, J. Appl. Meteorol., 43, 170-181, https://doi.org/10.1175/15200450(2004)043<0170:TKCPAU>2.0.CO;2, 2004.

Ke, W., Zhang, S., Wu, Y., Zhao, B., Wang, S., and Hao, J.: Assessing the future vehicle fleet electrification: The impacts on regional and Urban air quality, Environ. Sci. Technol., 51, 10071016, https://doi.org/10.1021/acs.est.6b04253, 2017.

Kim, M. J., Park, R. J., and Kim, J. J.: Urban air quality modeling with full $\mathrm{O}_{3}-\mathrm{NO}_{\mathrm{x}}$-VOC chemistry: Implications for $\mathrm{O}_{3}$ and $\mathrm{PM}$ air quality in a street canyon, Atmos. Environ., 47, 330-340, https://doi.org/10.1016/j.atmosenv.2011.10.059, 2012.

Kim, Y., Wu, Y., Seigneur, C., and Roustan, Y.: Multi-scale modeling of urban air pollution: development and application of a Street-in-Grid model (v1.0) by coupling MUNICH (v1.0) and Polair3D (v1.8.1), Geosci. Model Dev., 11, 611-629, https://doi.org/10.5194/gmd-11-611-2018, 2018.

Kuo, C.-W. and Tang, M.-L.: Relationship among service quality, corporate image, customer satisfaction and behaviroal intention for the elderly in high speed rail service, J. Adv. Transp., 47, 512-525, https://doi.org/10.1002/atr.179, 2011.

Kwak, K. H. and Baik, J. J.: Diurnal variation of $\mathrm{NO}_{\mathrm{x}}$ and ozone exchange between a street canyon and the overlying air, Atmos. Environ., 86, 120-128, https://doi.org/10.1016/j.atmosenv.2013.12.029, 2014.

Kwak, K. H., Baik, J. J., and Lee, K. Y.: Dispersion and photochemical evolution of reactive pollutants in street canyons, Atmos. Environ., 70, 98-107, https://doi.org/10.1016/j.atmosenv.2013.01.010, 2013.

Li, M., Zhang, Q., Kurokawa, J.-I., Woo, J.-H., He, K., Lu, Z., Ohara, T., Song, Y., Streets, D. G., Carmichael, G. R., Cheng, Y., Hong, C., Huo, H., Jiang, X., Kang, S., Liu, F., Su, H., and Zheng, B.: MIX: a mosaic Asian anthropogenic emission inventory under the international collaboration framework of the MICS-Asia and HTAP, Atmos. Chem. Phys., 17, 935-963, https://doi.org/10.5194/acp-17-935-2017, 2017.

Liu, Y. H., Ma, J. L., Li, L., Lin, X. F., Xu, W. J., and Ding, H.: A high temporal-spatial vehicle emission inventory based on detailed hourly traffic data in a mediumsized city of China, Environ. Pollut., 236, 324-333, https://doi.org/10.1016/j.envpol.2018.01.068, 2018.

MEP: Technical Guide of Air Quality Model Selection (Trial), Beijing, China, 2012.

MEP: Technical Guide of Air Pollutant Emission Inventory for On Road Vehicles (Trial), Beijing, China, 2014.

Min, X., Hu, J., Chen, Q., Zhang, T., and Zhang, Y.: Short-term traffic flow forecasting of urban network based on dynamic STARIMA model, IEEE Conf. Intell. Transp. Syst. Proceedings, ITSC, 100084, 461-466, https://doi.org/10.1109/ITSC.2009.5309741, 2009.

Mlawer, E. J., Taubman, S. J., Brown, P. D., Iacono, M. J. and Clough, S. A.: Radiative transfer for inhomogeneous atmospheres: RRTM, a validated correlated-k model for the longwave, J. Geophys. Res.-Atmos., 102, 16663-16682, https://doi.org/10.1029/97JD00237, 1997.

Morrison, H., Thompson, G., and Tatarskii, V.: Impact of Cloud Microphysics on the Development of Trailing Stratiform Precipitation in a Simulated Squall Line: Comparison of One- and 
Two-Moment Schemes, Mon. Weather Rev., 137, 991-1007, https://doi.org/10.1175/2008MWR2556.1, 2009.

National Bureau of Statistics of China: China Statistical Yearbook 2017, Beijing, People's Republic of China, 2017.

Pallavidino, L., Prandi, R., Bertello, A., Bracco, E., and Pavone, F.: Compilation of a road transport emission inventory for the Province of Turin: Advantages and key factors of a bottom-up approach, Atmos. Pollut. Res., 5, 648-655, https://doi.org/10.5094/APR.2014.074, 2014.

Park, S. J., Kim, J. J., Kim, M. J., Park, R. J., and Cheong, H. B.: Characteristics of flow and reactive pollutant dispersion in urban street canyons, Atmos. Environ., 108, 20-31, https://doi.org/10.1016/j.atmosenv.2015.02.065, 2015.

Pleim, J. E.: A Combined Local and Nonlocal Closure Model for the Atmospheric Boundary Layer. Part I: Model Description and Testing, J. Appl. Meteorol. Clim., 46, 1383-1395, https://doi.org/10.1175/JAM2539.1, 2007.

Righi, S., Lucialli, P., and Pollini, E.: Statistical and diagnostic evaluation of the ADMS-Urban model compared with an urban air quality monitoring network, Atmos. Environ., 43, 3850-3857, https://doi.org/10.1016/j.atmosenv.2009.05.016, 2009.

Saide, P., Zah, R., Osses, M., and Ossés de Eicker, M.: Spatial disaggregation of traffic emission inventories in large cities using simplified top-down methods, Atmos. Environ., 43, 4914-4923, https://doi.org/10.1016/j.atmosenv.2009.07.013, 2009.

Saikawa, E., Kurokawa, J., Takigawa, M., Borken-Kleefeld, J., Mauzerall, D. L., Horowitz, L. W., and Ohara, T.: The impact of China's vehicle emissions on regional air quality in 2000 and 2020: a scenario analysis, Atmos. Chem. Phys., 11, 9465-9484, https://doi.org/10.5194/acp-11-9465-2011, 2011.

Sanford, S. and He, D.: Some theoretical results concerning $\mathrm{O}_{3}$ $\mathrm{NO}_{\mathrm{x}}$-VOC chemistry and $\mathrm{NO}_{\mathrm{x}}$-VOC indicators, J. Geophys. Res., 107, 4659, https://doi.org/10.1029/2001JD001123, 2002.

Skamarock, W. C., Klemp, J. B., Dudhia, J., Gill, D. O., Barker, D. M., Duda, M. G., Huang, X.-Y., Wang, W., and Powers, J. G.: A description of the advanced research WRF version 3, NCAR Tech. Note NCAR/TN-475+ STR, 113 pp., 2008.

Sun, S., Jiang, W., and Gao, W.: Vehicle emission trends and spatial distribution in Shandong province, China, from 2000 to 2014, Atmos. Environ., 147, 190-199, https://doi.org/10.1016/j.atmosenv.2016.09.065, 2016.

Tang, G., Chao, N., Wang, Y., and Chen, J.: Vehicular emissions in China in 2006 and 2010, J. Environ. Sci.-China, 48, 179-192, https://doi.org/10.1016/j.jes.2016.01.031, 2016.

Underwood, R. T.: Speed, volume, and density relationship: quality and theory of traffic flow, Yale Bur. Highw. Traffic, 141-188, 1961.

Vlahogianni, E. I., Karlaftis, M. G., and Golias, J. C.: Short-term traffic forecasting: Where we are and where we're going, Transp. Res. C.-Emer., 43, 3-19, https://doi.org/10.1016/j.trc.2014.01.005, 2014.

Wang, H., Chen, C., Huang, C., and Fu, L.: On-road vehicle emission inventory and its uncertainty analysis for Shanghai, China, Sci. Total Environ., 398, 60-67, https://doi.org/10.1016/j.scitotenv.2008.01.038, 2008.

Wang, H., Fu, L., and Chen, J.: Developing a high-resolution vehicular emission inventory by integrating an emission model and a traffic model: Part 2-a case study in beijing, J. Air
Waste Manage., 60, 1471-1475, https://doi.org/10.3155/10473289.60.12.1471, 2010.

Wang, H., Ni, D., Chen, Q. Y., and Li, J.: Stochastic modeling of the equilibrium speed-density relationship, J. Adv. Transp., 47, 126-150, https://doi.org/10.1002/atr.172, 2013.

Wang, N., Lyu, X. P., Deng, X. J., Guo, H., Deng, T., Li, Y., Yin, C. Q., Li, F., and Wang, S. Q.: Assessment of regional air quality resulting from emission control in the Pearl River Delta region, southern China, Sci. Total Environ., 573, 1554-1565, https://doi.org/10.1016/j.scitotenv.2016.09.013, 2016.

Wang, R., Wang, K., Zhang, F., Gao, J., Li, Y. and Yue, T.: Emission Characteristics of Vehicles from National Roads and Provincial Roads in China, Environ. Sci., 38, 3-10, https://doi.org/10.13227/j.hjkx.201701087, 2017 (in Chinese).

Wang, T. and Xie, S.: Assessment of traffic-related air pollution in the urban streets before and during the 2008 Beijing Olympic Games traffic control period, Atmos. Environ., 43, 5682-5690, https://doi.org/10.1016/j.atmosenv.2009.07.034, 2009.

Wang, W.: Practical speed-flow relationship model of highway traffic-flow, J. Southeast Univ. Sci. Ed., 33, 487-491, 2003 (in Chinese).

$\mathrm{Wu}$, L.: ROE-1.0 release (Version 1.0), Zenodo, https://doi.org/10.5281/zenodo.3264859, 2019.

Wu, J., Sui, Y., and Wang, T.: Intelligent transport systems in China, P. I. Civil Eng.-Munic., 162, 25-32, https://doi.org/10.1680/muen.2009.162.1.25, 2009.

Xiong, G., Wang, K., Zhu, F., Cheng, C., An, X., and Xie, Z.: Parallel traffic management for the 2010 Asian Games, IEEE Intell. Syst., 25, 81-85, https://doi.org/10.1109/MIS.2010.87, 2010.

Xiu, A. and Pleim, J. E.: Development of a Land Surface Model. Part I: Application in a Mesoscale Meteorological Model, J. Appl. Meteorol., 40, 192-209, https://doi.org/10.1175/15200450(2001)040<0192:DOALSM>2.0.CO;2, 2001.

Xu, F., He, Z., Sha, Z., Zhuang, L., and Sun, W.: Assessing the Impact of Rainfall on Traffic Operation of Urban Road Network, Procedia Soc. Behav. Sci., 96, 82-89, https://doi.org/10.1016/j.sbspro.2013.08.012, 2013.

Yao, Z., Zhang, Y., Shen, X., Wang, X., Wu, Y., and He, K.: Impacts of temporary traffic control measures on vehicular emissions during the Asian Games in Guangzhou, China, J. Air Waste Manage., 63, 11-19, https://doi.org/10.1080/10962247.2012.724041, 2013.

Yarwood, G., Rao, S., Yocke, M., and Whitten, G. Z.: Updates to the carbon bond chemical mechanism: CB05, Rep. RT-0400675, 246 pp., available at: http://www.camx.com/files/cb05_final_report_ 120805.aspx (last access: 2 September 2019), 2005.

Ye, L., Wang, X., Fan, S., Chen, W., Chang, M., Zhou, S., Wu, Z., and Fan, Q.: Photochemical indicators of ozone sensitivity: application in the Pearl River Delta, China, Front. Environ. Sci. Eng., 10, 1-14, https://doi.org/10.1007/s11783-016-0887-1, 2016.

Zhang, F.: The current situation and development thinking of the intelligent transportation system in China, 2010 Int. Conf. Mech. Autom. Control Eng. MACE2010, 717, 2826-2829, https://doi.org/10.1109/MACE.2010.5536406, 2010.

Zhang, G., Mu, Y., Liu, J., Zhang, C., Zhang, Y., Zhang, Y., and Zhang, H.: Seasonal and diurnal variations of atmospheric peroxyacetyl nitrate, peroxypropionyl nitrate, and carbon tetrachloride in Beijing, J. Environ. Sci., 26, 65-74, https://doi.org/10.1016/S1001-0742(13)60382-4, 2014. 
Zhang, Q., Streets, D. G., Carmichael, G. R., He, K. B., Huo, H., Kannari, A., Klimont, Z., Park, I. S., Reddy, S., Fu, J. S., Chen, D., Duan, L., Lei, Y., Wang, L. T., and Yao, Z. L.: Asian emissions in 2006 for the NASA INTEX-B mission, Atmos. Chem. Phys., 9, 5131-5153, https://doi.org/10.5194/acp-9-5131-2009, 2009.

Zhang, S., Wu, Y., Liu, H., Wu, X., Zhou, Y., Yao, Z., Fu, L., He, K., and Hao, J.: Historical evaluation of vehicle emission control in Guangzhou based on a multiyear emission inventory, Atmos. Environ., 76, 32-42, https://doi.org/10.1016/j.atmosenv.2012.11.047, 2013.

Zhang, S., Wu, Y., Huang, R., Wang, J., Yan, H., Zheng, Y., and Hao, J.: High-resolution simulation of link-level vehicle emissions and concentrations for air pollutants in a trafficpopulated eastern Asian city, Atmos. Chem. Phys., 16, 99659981, https://doi.org/10.5194/acp-16-9965-2016, 2016.

Zhang, S., Niu, T., Wu, Y., Zhang, K. M., Wallington, T. J., Xie, Q., $\mathrm{Wu}, \mathrm{X}$., and $\mathrm{Xu}, \mathrm{H} .:$ Fine-grained vehicle emission management using intelligent transportation system data, Environ. Pollut., 241, 1027-1037, https://doi.org/10.1016/j.envpol.2018.06.016, 2018.

Zhang, Y., Bocquet, M., Mallet, V., Seigneur, C., and Baklanov, A.: Real-time air quality forecasting, part I: History, techniques, and current status, Atmos. Environ., 60, 632-655, https://doi.org/10.1016/j.atmosenv.2012.06.031, 2012.
Zhang, Y., Wang, X., Li, G., Yang, W., Huang, Z., Zhang, Z., Huang, X., Deng, W., Liu, T., Huang, Z., and Zhang, Z.: Emission factors of fine particles, carbonaceous aerosols and traces gases from road vehicles: Recent tests in an urban tunnel in the Pearl River Delta, China, Atmos. Environ., 122, 876-884, https://doi.org/10.1016/j.atmosenv.2015.08.024, 2015.

Zheng, B., Huo, H., Zhang, Q., Yao, Z. L., Wang, X. T., Yang, X. F., Liu, H., and He, K. B.: High-resolution mapping of vehicle emissions in China in 2008, Atmos. Chem. Phys., 14, 9787-9805, https://doi.org/10.5194/acp-14-9787-2014, 2014.

Zheng, J., Che, W., Wang, X., Louie, P., and Zhong, L.: Roadnetwork-based spatial allocation of on-road mobile source emissions in the pearl river delta region, China, and comparisons with population-based approach, J. Air Waste Manage., 59, 14051416, https://doi.org/10.3155/1047-3289.59.12.1405, 2009a.

Zheng, J., Zhang, L., Che, W., Zheng, Z., and Yin, S.: A highly resolved temporal and spatial air pollutant emission inventory for the Pearl River Delta region, China and its uncertainty assessment, Atmos. Environ., 43, 5112-5122, https://doi.org/10.1016/j.atmosenv.2009.04.060, 2009 b.

Zhong, J., Cai, X. M., and Bloss, W. J.: Coupling dynamics and chemistry in the air pollution modelling of street canyons: A review, Environ. Pollut., 214, 690-704, https://doi.org/10.1016/j.envpol.2016.04.052, 2016. 